\title{
Das Inszenieren von authentischen Dramentexten im Fremdsprachenunterricht Deutsch der Oberstufe. Eine drama- und theaterpädagogische Projektarbeit für die erste Klasse einer weiterführenden norwegischen Sportschule anhand von dramatischen Tierfabeln
}

Marta Parés

Bardufoss Videregående Skole

\section{Zusammenfassung}

Zwei theoretische Bausteine bilden den Ausgangspunkt der vorliegenden Arbeit ${ }^{1}$ : Einerseits bieten authentische Dramentexte bzw. dramatische Tierfabeln eine gute didaktische Ergänzung zu den norwegischen Lehrbüchern für Deutsch (Niveau II) an wie etwa Gedichte oder Prosatexte. Andererseits leisten drama- und theaterpädagogische Ansätze im Fremdsprachenunterricht Deutsch (FSU) einen Beitrag sowohl zur Förderung allgemeiner Grundfertigkeiten als auch zum Erreichen überfachlicher Lernziele. Als Beispiel für einen theaterorientierten FSU im Fach Deutsch in der norwegischen Oberstufe wird eine sechswöchige drama- und theaterpädagogische Projektarbeit für die erste Klasse einer weiterführenden Sportschule anhand von fünf dramatischen Tierfabeln präsentiert. Zur empirischen Überprüfung der theoretischen Annahmen dieses Theaterprojekts werden drei Audioaufnahmen und ein Follow-up-Schüler-Fragebogen als Datenerhebungs- und Auswertungsmethode ausgewählt und deren inhaltliche Ergebnisse dargestellt, analysiert und ausgewertet. Abschließend werden zwei Desiderate für künftige Forschungsfelder beleuchtet.

\section{Schlüsselwörter}

Theaterpädagogik, Dramapädagogik, Fremdsprachenunterricht Deutsch, norwegische Oberstufe, fachübergreifende Lernziele, Aussprachekompetenz, Zischlaute, Motivation.

\footnotetext{
${ }^{1}$ Der vorliegende Beitrag ist eine verkürzte Version einer Masterarbeit, deren Online-Ausgabe in voller Länge unter https://hiof.brage.unit.no/hiof-xmlui/handle/11250/2616892 zur Verfügung steht.
} 


\section{Problemstellung und Relevanz des Untersuchungsfeldes}

Seit der kommunikativen Wende in der Fremdsprachendidaktik überwiegt ab den frühen 1970er Jahren ein „,kommunikativer Zeitgeist“ (Edmondson \& House, 2011, S. 122) im Fremdsprachenunterricht (im Folgenden FSU). Kommunikative Kompetenz in der Zielsprache sollte mithin im Handlungsraum Klassenzimmer umgesetzt werden können (vgl. Legutke, 2008, S. 33ff.). Dies bedeutet, dass die Lernenden innerhalb des Unterrichts in die Lage versetzt werden sollen, ihre eigenen kommunikativen Intentionen in der Fremdsprache angemessen mitzuteilen und die ihrer Interaktionspartner richtig zu verstehen sowie selbstbewusst und lernend ihre eigene Rede zu problematisieren (vgl. Rigotti, 2010, S. 7; vgl. Legutke, 2008, S. 20).

Richtet man den Blick auf die anzuvisierenden Hauptlernziele im norwegischen Lehrplan der Fremdsprache Deutsch auf dem Niveau II für die Oberstufe (Lareplan $i$ fremmedspråk nivå II), zählen zu den kommunikativen Fertigkeiten in der Zielsprache, neben dem Leseverständnis von authentischen Texten unterschiedlicher Textsorten, Gattungen und Textformen, das gelungene Sprechen und Präsentieren in formellen und informellen Zusammenhängen sowie der Gebrauch von kommunikativen Strategien² (vgl.

Utdanningsdirektoratet, 2006, S. 5).

Man sollte meinen, dass Lehrbücher für den FSU Deutsch in der Oberstufe, die für den erwähnten Lehrplan entwickelt wurden, dessen Richtlinien strikt einhalten. Doch das Gegenteil ist nicht selten der Fall: In den ausgearbeiteten Textkorpora aus den kürzlich publizierten norwegischen Textbüchern für das Fach Deutsch II (Tysk Nivå II) in der ersten Klasse $(V g l)$ der Oberstufe tritt ein auffallender Mangel sowohl an authentischen literarischen Texten als auch an systematischen Aufgaben und Übungen zu einer gezielten Förderung der Aussprache hervor. Demzufolge kann es der Lehrperson sehr schwer fallen, ihren Schülern die Gattung Drama und das Inszenieren von Theaterstücken in der Zielsprache Deutsch nahezubringen, wenn Dramentexte keinen Einzug in das jeweilige Lehrwerk für das Fach finden. Mangelhafte Ausspracheübungen in den norwegischen Lehrbüchern für Deutsch II in

\footnotetext{
${ }^{2}$ Laut Europarat (2001) werden „Kommunikations- und Kompensationsstrategien“ von den Sprachverwendenden dazu eingesetzt, um rezeptive, interaktive, produktive und sprachmittelnde Aktivitäten erfolgreich zu erledigen (vgl. Europarat, 2001, S. 63ff.). Hier scheint m. E. einleuchtend zu sein, dass die betreffenden Strategien auf die sog. „Hör-, Sprech-, Lese- und Schreibstrategien“ („lytte-, tale-, lese- og skrivestrategier") der oben angeführten kommunikativen Lernziele übertragen werden können (Utdanningsdirektoratet, 2006, S. 5).
} 
der Klassenstufe 1 (Oberstufe) bereiten den Deutschlehrern überdies große Schwierigkeiten, wenn sie im Klassenzimmer phonetische Schwerpunkte für die anzustrebende ,gute Aussprache und Intonation“ (,god uttale og intonasjon“") $)^{3}$ trainieren wollen oder wenn den jungen Lernenden ihre fehlerhaften, durch die L1 meistens ungewohnten Aussprachemuster bewusst gemacht werden sollen.

Vom verfügbaren Textrepertoire in den norwegischen Deutschlehrbüchern für die Oberstufe in der ersten Klasse ${ }^{4}$ sind Dramentexte - mit Ausnahme von einem Lehrbuch ausgeschlossen. Dies steht allerdings nicht in Übereinstimmung mit den jüngsten Studien zur Fremdsprachendidaktik. Zum einen plädiert die Forschung im Bereich der Kinder- und Jugendliteratur für eine unterrichtliche Auseinandersetzung mit Dramentexten (vgl. Passon, 2014, S. 26, in Anlehnung an Rüdiger Ahrens et al.). Zum anderen gelten zahlreiche Theaterprojekte im DaF-Unterricht sowie die vielen aktuellen Publikationen, Tagungen, Workshops und Kongresse für drama- und theaterpädagogische Fremdsprachendidaktik als Beweis dafür, dass Theaterspielen von wesentlicher Bedeutung für den schulischen FSU Deutsch ist bzw. sein sollte.

Aus dem Forschungsstand der Drama- und Theaterpädagogik lässt sich sodann ableiten, dass dramapädagogische Ansätze nicht nur gewinnbringend für die Förderung authentischer mündlicher Kommunikation in der Zielsprache sind. Die Schulung der Aussprache erlangt u.a. dann Bedeutung, wenn es um die Inszenierung eines Theaterstückes geht. In den Repliken geht das Trainieren der eigenen Stimme und ihres kommunikativen Potenzials mit dem Hineinversetzen in Rollen einher und wird dadurch in weitere sinnvolle Zusammenhänge einbezogen (vgl. Elis, 2015, S. 99f.). Das Theaterspielen und dramapädagogische Übungen bedienen sich zudem sowohl verbaler als auch nonverbaler Elemente (vgl. ebd., S. 100f.). So erfahren Lernende beim Spielen mit paralinguistischen Aspekten wie z. B. Gestik, Mimik und Körperhaltung, wie viel ihr Körper ohne Worte kommunizieren kann.

\footnotetext{
${ }^{3}$ Utdanningsdirektoratet, 2006, S. 5.

${ }^{4}$ Hier beziehe ich mich auf alle Kursbücher bzw. Lehrbücher für das Fach Deutsch II (Klassenstufe 1), die ab dem Jahr 2006 von norwegischen Verlagen publiziert worden sind, und zwar Ankunft 1, Einfach Deutsch 1, Weitblick 2 (Kapitel 1 - Kapitel 8) und Weiter geht's (Kapitel 1 - Kapitel 9). Die aufgezeigte Kapitelauswahl entspricht dem Vorschlag für eine Jahresplanung in der ersten Klasse zu Weitblick 2 und Weiter geht's (vgl. Aschehoug, 2012; vgl. auch Samlaget, 2012).
} 


\section{Nordic Journal of Modern Language Methodology}

2019, 7 (1), 165-220 (Part B - Not peer reviewed)

Dessen eingedenk stellt sich die Frage, inwieweit die szenische Umsetzung von authentischen Dramentexten bzw. dramatischen Tierfabeln im Fremdsprachenunterricht Deutsch der norwegischen Oberstufe (Jahrgang 1)

1. einen Beitrag zu fachübergreifenden Lernzielen wie Sprachaufmerksamkeit, Sprachbewusstheit und Sensibilisierung in sozialen Lernprozessen durch dramaund theaterpädagogische Ansätze leisten kann;

2. die jungen Lernenden dazu befähigt, im entspannten Rahmen des Theaterspielens und in Zusammenarbeit mit ihren Mitspielern die Angst vor dem Sprechen und/oder vor einem Bloßstellen abzubauen, ein hohes Selbstvertrauen herauszubilden und somit die innere Motivation zum Deutschlernen zu steigern;

3. den Schülern zur Verbesserung bzw. zur Korrektur von fehlerhaft erworbenen Aussprachemustern im Deutschen verhilft.

Ausgehend von der Grundidee, dass der Fremdsprachenunterricht als ganzheitlich orientierter und organisierter Lernprozess aufzufassen ist, müssen m. E. in einer Projektarbeit unter Einbeziehung von Drama- und Theaterpädagogik didaktisch-methodische Prinzipien, klar formulierte Lernziele, Rahmenbedingungen und gut strukturierte Unterrichtsblöcke miteinander verzahnt werden. Auf diese Weise wird die vorliegende drama- und theaterpädagogische Projektarbeit nicht allein auf die Frage antworten, ob die Inszenierung von Tierfabeln mit Mitteln der Drama- und Theaterpädagogik dem Fremdsprachenunterricht Deutsch in der Oberstufe einen kommunikativen Mehrwert bietet. Dieses Theaterprojekt soll außerdem den Nachweis erbringen, inwieweit fremdsprachliche Drama- und Theaterpädagogik in Kombination mit Dramentexten - in diesem Fall dramatischen Tierfabeln - einem kompetenzorientierten Fremdsprachenunterricht Deutsch in der ersten Klasse der norwegischen Oberstufe Raum geben kann.

Somit widmet sich diese Arbeit zunächst der Bedeutung von dramatischen Texten bzw. Tierfabeln im Fremdsprachenunterricht Deutsch in der Oberstufe (Kapitel 2). In einem zweiten Schritt wird zum einen das Theaterprojekt unter Berücksichtigung der oben erwähnten Forschungsfragen sowie der strukturierten Beschreibung des Unterrichtsdesigns (Kapitel 3.1) vorgestellt. Zum anderen werden quantitative Datenerhebungsverfahren beschrieben (Kapitel 3.2). Dabei wird die Sichtweise der Schüler mittels drei Audioaufnahmen (Kapitel 3.2.1) und eines Follow-up-Fragebogens (Kapitel 3.2.2) in 


\section{Nordic Journal of Modern Language Methodology}

2019, 7 (1), 165-220 (Part B - Not peer reviewed)

Abbildungen und Tabellen dargestellt, systematisch analysiert und ausgewertet. Das letzte Kapitel soll Ausblick auf den vielfältigen Einsatz von Dramentexten im kommunikativen FSU Deutsch in der Oberstufe geben (Kapitel 4).

\section{Zum Stellenwert von dramatischen Tierfabeln im Fremdsprachen- unterricht Deutsch der norwegischen Oberstufe}

Wie im Kapitel 1 angedeutet, lassen sich Dramentexte in den aktuellen norwegischen Deutschlehrbüchern für die erste Klasse in der Sekundarstufe II kaum finden. Nichtsdestotrotz wird der Behandlung von dramatischen Texten im FSU ein hoher Stellenwert beigemessen. Zum einen können allerlei szenische Kommunikationsformen mit ihrer Einbettung in situative Kontexte zu einem Vorbild für einen kontextgebundenen Spracherwerb beitragen. Zum anderen gilt jede Inszenierung im Klassenzimmer als Gestaltungsmöglichkeit zu einem handlungs- und produktionsorientierten Unterricht (vgl. Passon, 2014, S. 26, in Anlehnung an Rüdiger Ahrens et al.).

Durch ihre kombiniert auftretenden epischen und dramatischen Elemente entfaltet ebenfalls die Fabeldichtung ein derartiges performatives Potenzial. Die tierischen Hauptfiguren dieser Vers- oder Prosaerzählungen handeln oft nach festen menschlichen Verhaltensmustern und haben am Ende ihrer Geschichten das letzte Wort. Denn hier wird am Beispiel tierischer Beziehungen eine allgemein anerkannte Wahrheit oder eine praktische Lebensweisheit dadurch veranschaulicht, dass die Zuhörer etwas lernen können oder einfach zum Nachdenken angeregt werden (vgl. Deutsches Universalwörterbuch online, 2018; dazu vgl. Schulze, 2012, S. 175). Anders ausgedrückt, repräsentiert jedes Tier ein festes Verhaltensmuster, an dem die Lernenden unterschiedliche Handlungsmöglichkeiten als Spiegel ihres eigenen Wesens erkennen können. So lässt sich beispielsweise „im Fuchs die eigene schlaue Unverschämtheit, im Wolf seine rücksichtslose Gier nach Genuss und Besitz, im Hahn de[r] aufgeblähte Stolz“ (Haas, 2003, S. 123) erblicken. Diese typisch menschlichen Charaktermerkmale begünstigen folglich auch nicht nur das Zusammentreffen von zwei Welten, nämlich der Erfahrungswelt der jungen Lerner und der Literaturwelt. Durch den Umgang mit dramatischen Tierfabeln erhalten die Lernenden vielmehr die Möglichkeit, bekannte Rollen auszuprobieren, sie zurückzuweisen, sich von ihnen zu distanzieren oder sich mit ihnen zu identifizieren. 


\section{Nordic Journal of Modern Language Methodology}

2019, 7 (1), 165-220 (Part B - Not peer reviewed)

Den dramatischen Tierfabeln wohnt aber dennoch nicht nur eine belehrende Funktion inne, sondern solche Dramentexte neigen zum Teil auch zur Unterhaltung. Dabei kann eine witzige Pointe oder eine nicht vorgesehene Wendung durchaus ausschlaggebend sein. Die Wirkung geht nicht zuletzt von dem Überraschungseffekt aus, mit dem plötzlich eine anerkannte Wahrheit oder praktische Lebensweisheit erscheint und eine sogenannte „(Beinahe)-Katastrophe“ (Steinlein, 2004, S. 324) ausgelöst wird. Wahrheit und Komik werden oft in ein essentielles Bedingungsverhältnis zueinander gebracht und gehen durch eine unerwartete Verrückung bzw. überraschende Schlusswendung ineinander über. Komisches macht sich dementsprechend als Lachgefühl geltend, welches nur empfunden oder auch externalisiert wird (vgl. ebd., S. 323, in Anlehnung an András Horn). Als wirkungsästhetische Kategorie schafft solches Lachen eine Sphäre kollektiver Zugehörigkeit, sowohl bei den Schauspielern als auch bei den Zuschauern.

Weiterhin haben sich Tierfabeln bisher einen gewissen Eingang in den Fremdsprachenunterricht Deutsch der norwegischen Oberstufe verschafft. In einem der oben untersuchten Lehrbücher für Deutsch II in der Sekundarstufe II (Weiter geht's) sind vier epische Tierfabeln als Lektüreempfehlungen zu finden und lassen sich somit der Begrifflichkeit intendierte Kinder- und Jugendlektüre zuordnen (vgl. Ewers, 2012, S. 5). Dies erweist sich allerdings als durchaus problematisch, weil das Lesen von dramatischer Literatur als Übergangsphase zur Inszenierung gelten dürfte (vgl. Taube, 2005, S. 572).

Klare Vorteile der Nutzung von dramatischen Tierfabeln im vorliegenden Unterrichtsprojekt spiegeln sich ebenfalls in den gegebenen Aussagen der Beteiligten bei der durchgeführten repräsentativen Befragung mittels eines Fragebogens wider. Auf die Frage: „Welchen Unterschied hätte es gemacht, wenn wir statt einer Tierfabel ein klassisches Drama gespielt hätten?“،, betonten die meisten Äußerungen die sprachliche Angemessenheit der verwendeten Dramentexte, das sofortige Erkennen von allgemeingültigen Handlungsmustern bei den tierischen Hauptfiguren sowie die persönliche Einfühlung durch das Erleben der Identifikation mit den jeweiligen Rollenfiguren. Wie der folgenden Abbildung zu entnehmen ist, begründeten 10 von 24 Befragten (42\%) ihre Meinung auf dreierlei Weise positiv für den Einsatz von Tierfabeln und 11 von 24 Befragten (46\%) sprachen sich auf zweierlei Weise für die Verwendung von Fabeldichtungen im FSU aus, was eine (starke) positive Änderung ausmachte: 


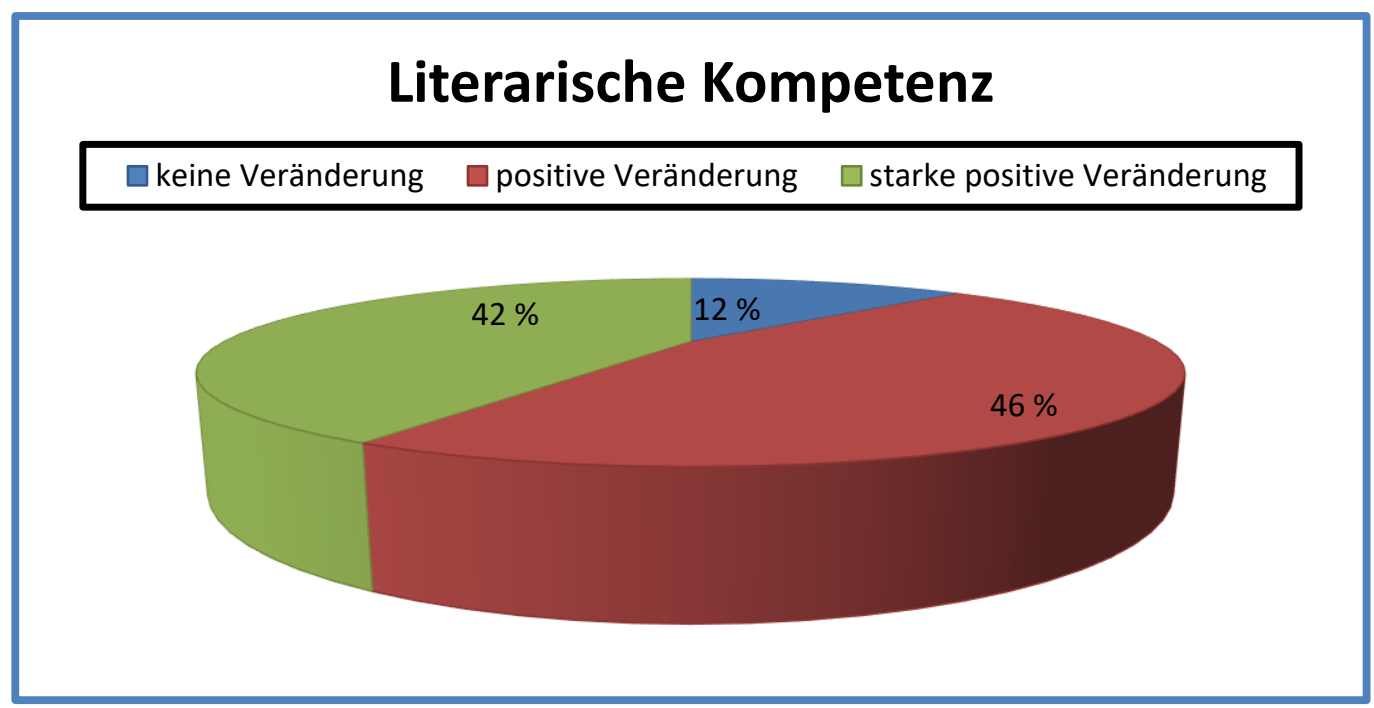

Abb. 1: Kategorie 6 - Literarische Kompetenz

\section{Die Projektarbeit}

\subsection{Methodische Vorgehensweise und Zielsetzung}

Der didaktische Aufbau, welcher dem Unterrichtskonzept dieser Projektarbeit zugrunde liegt, wurde für eine Gruppengröße von 24 Schülern in der ersten Klasse der Sekundarstufe II entwickelt und umfasste einen Zeitraum von sechs Wochen ${ }^{5}$ (vom 11. Mai bis 15. Juni 2016). Das vorliegende Theaterprojekt ergibt sich gleichfalls aus drei Phasen bzw.

Unterrichtsblöcken ${ }^{6}$ (Inspiration, Spielfähigkeit und Reflexion) mit insgesamt 10

Unterrichtsstunden von je einer Doppelstunde (90 Minuten) inklusive einer 10-minütigen

Pause (s. Anhänge, 1. Probeplan für die Inszenierung von fünf dramatischen Tierfabeln von Olaf Heuser).

\footnotetext{
${ }^{5}$ Die angebrachte Beschränkung meiner Projektarbeit auf die erste Klasse in der norwegischen Oberstufe sowie auf einen sechswöchigen Unterricht scheint mir wiederum aus zweierlei Gründen wichtig zu sein: Einerseits muss man meine bislang gesammelte Berufserfahrung als Fremdsprachenlehrerin im Fach Deutsch mit der betreffenden Jahrgangsstufe nennen. Andererseits hatte ich für dieses Theaterprojekt nur einen begrenzten Umfang in zeitlicher und inhaltlicher Hinsicht zur Verfügung. Dies spiegelte sich darin wider, dass die vorliegende Projektarbeit sich über zehn einzelne Unterrichtsstunden von jeweils 90 Minuten erstrecken und mit einer meiner Klassengruppen in der norwegischen Oberstufe durchgeführt werden musste.

${ }^{6}$ Da eine ausführliche Darstellung sämtlicher Unterrichtsstunden den Rahmen der vorliegenden Arbeit überschreiten würde, werden sie tabellarisch skizziert (s. Anhänge, 1. Unterrichtsblöcke). Ferner ist hier wichtig darauf hinzuweisen, dass sich viele der verwendeten Übungen zum szenischen Spiel auf Levy (2013) berufen.
} 


\section{Nordic Journal of Modern Language Methodology}

2019, 7 (1), 165-220 (Part B - Not peer reviewed)

Die Inszenierung von fünf dramatischen Fabeln lässt sich im drama- und theaterpädagogischen Sinne gut strukturieren und durchführen. In den ersten drei Unterrichtsstunden wird auf affektive, psychomotorische und literarische Kompetenzen, auf die Auseinandersetzung mit dem ersten Bühnenauftritt und auf die Rollenvergabe großer Wert gelegt. In der ersten Unterrichtsstunde (1. US) sollen folgende drama- und theaterpädagogische Ansätze die Aktivierung und Verknüpfung von Vorwissen mit den Lerninhalten bezwecken: kurz gestaltete szenische Improvisationen, spielerischer Einsatz von Wortschatz zu einem bekannten Thema, persönliche Entdeckung der eigenen Vorstellungskraft und Aussagefähigkeit sowie eine Reflexionsrunde über das Gelernte. In der 2. US lässt sich ein theaterpädagogisches Fundament legen, indem durch Theaterspiele die Schüler für ihre Körpersprache und Körperwahrnehmung sensibilisiert werden. Bei der Synchronisation eines stummen Kurzfilmes stellen sich die Lernenden weiterhin szenischen Herausforderungen. Dadurch können die Lernenden es zustande bringen, ihr Vertrauen im Team aufzubauen, Selbst- und Rollenbilder auszuprobieren, sich von Klischees und Stereotypen zu befreien und die eigene Kreativität und mentale Flexibilität auszuleben. Die letzte US der ersten Phase widmet sich zudem der Förderung literarischer Rezeptionskompetenz, der Körperwahrnehmung sowie der Rollenvergabe. Zur Rollenzuordnung werden die Beteiligten dazu aufgefordert, die Rollenauswahl in Kleingruppen eingehend zu besprechen.

In der zweiten Phase wird das Augenmerk auf theaterästhetische Aspekte und funktionale kommunikative Kompetenzen gerichtet. Hier erweisen sich Inszenierungstechniken, Theaterspiele und Ausspracheübungen als didaktische Möglichkeiten zur Annäherung an die besetzten Rollen, zum Gedächtnis- und Konzentrationstraining, zur Schärfung der Sinne sowie zum Abbau von Hemmungen. Soziale Interaktionen, die performative Fremdsprachenkompetenz sowie die Grundfertigkeiten Hör-Seh-Verstehen, Sprechen und Lesen stehen gleichfalls im Fokus.

Im Übergang von der 3. US zur 4. US und in der 7. US wird autonomes Lernen dahingehend gefördert, dass die Lernenden sich im außerschulischen Kontext (3./4. US) und im Unterricht (7. US) auf ihre Art und Weise und im eigenen Tempo mit den ausgewählten Rollen vertraut machen sollen. In der zweiten Phase werden die Schüler darüber hinaus darum gebeten, ihre Rollen laut vorzulesen und sich dabei aufzunehmen. Die erste Audioaufnahme 


\section{Nordic Journal of Modern Language Methodology}

2019, 7 (1), 165-220 (Part B - Not peer reviewed)

wird in der 6. US ohne Besprechung phonetischer Regeln durchgeführt, während die zweite Audioaufnahme nach der Sichtbarmachung wichtiger Ausspracheprobleme etwa mit bestimmten Zischlauten ([s]/[z], [J], [ç]/[x]) und Lautkombinationen $([\mathrm{ks}] /[\mathrm{ts}])$ stattfindet. Die Audioaufnahmen der vorgelesenen Rollen vollziehen sich im schulischen Bereich mit Text (6. US) und ohne Text (8. US). Somit gelten die zwei kontextbezogenen Audioaufnahmen (ohne Besprechung mit Text und mit Besprechung ohne Text) als guter Beweis für die Förderung von funktionalen kommunikativen Fremdsprachenkompetenzen durch unterschiedliche Übungen zum szenischen Spiel, und zwar die produktive Grundfertigkeit des Sprechens im Allgemeinen und die phonetische Kompetenz im Besonderen. Die zweite Phase der Spielfähigkeit schließt mit einer Generalprobe (8. US) und der Uraufführung (9. US) ab.

Die Rückmeldung zum Theaterprojekt anhand eines Fragebogens (9. US) sowie die letzte Audioaufnahme eines unbekannten literarischen Textes zur Überprüfung und Festigung des phonetischen Wissens um die im Unterricht bereits angegangenen Sibilanten (10. US) gehören zur letzten Phase der Reflexion mit dem Schwerpunkt der Ergebnissicherung. Im Übrigen kann man pointieren, dass die Phasen Spielfähigkeit und Reflexion voneinander abhängig sind. Darin geht es stets darum, einzelne Szenen mithilfe von Theaterspielen oder szenischen Übungen in Teamarbeit anzulegen, sie anschließend der Klassengruppe vorzuführen und die Ergebnisse der Kleingruppen im Plenum vorzustellen und zu diskutieren.

Zusammenfassend lässt sich behaupten, dass die dargestellte methodische Vorgehensweise es den Schülern anhand eines Theaterprojekts ermöglicht, individuelle und kollektive Erfahrungen zu sammeln und auszutauschen, funktionale kommunikative Kompetenzen in der Fremdsprache zu verbessern sowie performative Fremdsprachenkompetenz zu sichern.

\subsection{Datenerhebungsverfahren}

Die Wahl der Datenerhebungs- und Auswertungsmethoden ergibt sich demnach nicht nur aus der bereits in Kapitel 1 genannten Fragestellung, sondern auch aus den grundlegenden theoretischen Annahmen zur Förderung von kommunikativer Fremdsprachenkompetenz durch Drama- und Theaterpädagogik. Ferner beruht sie auf dem Umstand, dass es sich bei der Zielgruppe um Schüler in der ersten Klasse einer weiterführenden Sportschule handelt. An dieser Stelle stellt sich nun die Frage, wie sich die formulierten Forschungsfragen sowie die 


\section{Nordic Journal of Modern Language Methodology}

2019, 7 (1), 165-220 (Part B - Not peer reviewed)

theoretischen Postulate erfassen lassen. Dafür bedarf es passender Datenerhebungsmethoden, mit denen sich die oben aufgestellten Forschungsfragen aus unterschiedlichen Perspektiven beleuchten lassen. Dies wird im Nachstehenden durch drei Audioaufnahmen und einen Follow-up-Schüler-Fragebogen mit Einstellungs- und Verhaltensfragen konkret umgesetzt.

\subsubsection{Audioaufnahmen}

Eine korrekte Aussprache ist auch Voraussetzung für eine gute kommunikative Sprachkompetenz in der Zielsprache. Sie ermöglicht es den Lernenden, sich verständlich und intentionsgemäß auszudrücken. Das Erlernen einer Fremdsprache fordert aber nicht nur, grammatische Regeln zu beherrschen oder neuen Wortschatz zu erwerben, sondern auch ungewohnte Laute und Lautverbindungen zu automatisieren und korrekt produzieren zu können. Wenn die Lerner nicht auf ihre fremde Aussprache achten, schleichen sich sofort normabweichende Aussprachemuster ein, welche Gefahr laufen zu fossilisieren, und somit trotz langer Lernzeit in der mündlichen Produktion häufig vorkommen oder sogar erhalten bleiben (vgl. Dentler, 2000, S. 93; vgl. auch Edmondson \& House, 2000, S. 233f.). Grundlegend scheint es möglicherweise vielfältige individuell unterschiedliche Faktoren wie die Sprechangst oder die Identitätswahrung zu geben, die sich bei günstiger Konstellation und Kombination auf den Sprachlernprozess in der Fremdsprache auswirken. Häufig liegt der Grund für zielsprachliche Ausspracheprobleme einfach darin, dass die Lerner ähnliche Laute und Lautkombinationen der Zielsprache die ihrer Muttersprache angleichen oder sie gar nicht erst richtig wahrnehmen (vgl. Bohn, 1998, S. 5).

Setzt man sich für ein drama- und theaterpädagogisches Projekt im FSU der norwegischen Oberstufe ein, scheint die Verbesserung der Aussprache des Deutschen auch ein sinnvolles Lernziel zu sein. Zur Eingrenzung dieses Forschungsgegenstands soll die Artikulation bestimmter anspruchsvoller Laute und Lautverbindungen überprüft werden. Infolgedessen beschränkt sich das Forschungsfeld dieser Arbeit auf die deutschen Zischlaute /z/, /s/, /ç/, /x/, / / / sowie die deutschen Lautkombinationen /ks/ und /ts/. Zweifellos bereiten den norwegischen Schülern die angegebenen Sibilanten Schwierigkeiten bei ihrer zielsprachlichen Aussprache. Obwohl sich ähnliche oder gleiche Laute im Norwegischen 
finden (vgl. Eggesbø Abrahamsen \& Morland, 2012, S. 11), werden diese Laute in ähnlichen Lautkombinationen im Deutschen oft nicht korrekt artikuliert?

Zur Dokumentation der oben erwähnten fonetischen Phänomene wird das Arbeiten mit Textkorpora ausgewählt. Hierzu werden zwei Texte analysiert: Der eine betrifft die Sprechrollen der Fabeln, welche die Schüler auswendig lernen sollen. Diese Sprechrollen werden zweimal in Form von Audioaufnahmen aufgezeichnet. Die erste Audioaufnahme (A1) gilt als Ausgangspunkt für die Aussprachekompetenz jedes Teilnehmenden in Bezug auf die zu untersuchenden Laute und Lautkombinationen, da sich die Schüler zum ersten Mal und unvorbereitet mit den betreffenden Zischlauten und Lautverbindungen auseinandersetzen müssen. Da die Sprechrollen den Schülern bei der zweiten Audioaufnahme (A2) bereits bekannt sind, wird nun eine Verbesserung in der Aussprache der vorliegenden fonetischen Phänomene erwartet. Der andere Text wird in Form von einer dritten Audioaufnahme (A3) aufgezeichnet. Dieser Text ist den Schülern völlig unbekannt und soll in Abschnitten laut vorgelesen und aufgezeichnet werden. Jeder Schüler trägt die Verantwortung für einen Textabschnitt, welcher seinerseits eine Fülle von den zu analysierenden Zischlauten und Lautverbindungen umfasst.

Der nächste Schritt nach der unmittelbaren Beobachtung durch die drei Audioaufnahmen besteht darin, die Rohdaten zu klassifizieren. Hierbei geht es um die Einordnung von korrekt ausgesprochenen Zischlauten und Lautkombinationen, die relevant für die Untersuchung dieser Arbeit sind. Zur Erstellung von ausschlaggebenden Kategorien für die zu untersuchenden fonetischen Phänomene wird jedem individuellen Schüler (S) eine Zahl zugeordnet; mit einem Farbcode wird jeder Schüler in eine von drei Leistungsgruppen ${ }^{8}$

\footnotetext{
${ }^{7}$ Hier lassen sich drei treffende Beispiele anführen: Während „Konklusion“ mit /z/ ausgesprochen werden soll, wird das entsprechende norwegische Wort „konklusjon“ mit / // artikuliert. Demzufolge kommt zuweilen vor, dass das deutsche „Konklusion“ mit / // anstatt mit /z/ artikuliert wird. Ähnliches gilt für das deutsche Wort „Intuition“ /Intui'tsjo:n/, dessen entsprechendes norwegisches Wort ,intuisjon“ mit / $/$ / artikuliert wird und somit das deutsche Wort oft mit / / / anstatt mit /ts/ produziert wird. Schließlich scheint der deutsche stimmhafte alveolare Frikativ/z/ bei den norwegischen Schülern insofern anspruchsvoll zu sein, als dass dieser Reibelaut vor allem am Wortanfang stimmlos artikuliert wird. Somit werden beispielsweise die Verben „sehen“ und „stehen“ oder das Substantiv „Spiel“ mit /s/ ausgesprochen, weil die entsprechenden norwegischen Verben „så“ und „stä“ und das entsprechende norwegische Nomen ,spill“ mit /s/ artikuliert werden soll.

${ }^{8}$ Die Schülereinstufung nach der Leistungsfähigkeit folgt dem Kriterium der Fachleistungen der Schüler im Laufe des Schuljahres 2015-2016. Somit werden die jeweiligen Leistungen der teilnehmenden Schüler als „überdurchschnittlich“, „durchschnittlich“ oder „unterdurchschnittlich“ eingestuft, je nachdem, ob sie die Gesamtnoten 6-5, 4-3 oder 2 im Fach Deutsch II erhalten haben. Die Schüler werden ihrerseits grün, orange und gelb markiert (s. Tabelle 1 - 4). Die Gesamtanzahl der teilnehmenden Schüler in jeder Einstufung wird durch „,n“
} 
eingestuft und erst dann in zwei Tabellen (s. Tabelle 1 und Tabelle 3) in der Spalte 1 (,Schüler“) aufgelistet, wenn er bzw. sie sowohl bei den drei Audioaufnahmen als auch bei der Ausfüllung des Fragebogens teilgenommen hat. Darüber hinaus werden die zu analysierenden Laute und Lautkombinationen, die in jeder Sprechrolle und jedem Textabschnitt zu finden sind, einzeln gezählt. Die Summe der jeweiligen Laute und Lautkombinationen werden mit einer Zahl in zwei Tabellen (s. Tabelle 1 und Tabelle 3) in die Spalte 2 („Laute“) eingetragen. Ausgehend von dieser Anzahl werden die richtig registrierten Laute und Lautkombinationen bei jedem Schüler gesammelt und mit drei Werten (Zahl, Prozentsatz in Prozentpunkten und Rangordnung ${ }^{9}$ ) in zwei Tabellen (s. Tabelle 1 und Tabelle 3 ) in der Spalte 3 und 6 (,richtig ausgesprochen“), in der Spalte 4 und 7 (,korrekt“) und in der Spalte 5 und 8 (,Rang“) zusammengeführt. Außerdem wird die prozentuale Änderung zwischen dem ersten und dem zweiten Prozentsatz (s. Tabelle 1, Spalte 9) einerseits und zwischen dem ersten und dem dritten Prozentsatz (s. Tabelle 3, Spalte 6) andererseits in Prozentpunkten berechnet. Somit wird die prozentuale Zunahme oder Abnahme um denselben Prozentsatz (,Änderung“) angegeben, woraufhin die Verbesserung oder Verschlechterung der Aussprachekompetenz in Bezug auf die zu analysierenden Laute und Lautkombinationen festgestellt wird.

In Tabelle 1 finden sich die Ergebnisse für das aufgezeichnete Vorlesen der Sprechrollen ohne Vorbereitung (A1) und mit Vorbereitung (A2). Im Mittel ergibt sich für die leistungsstarken Schüler eine Spannweite der korrekt artikulierten Laute und Lautkombinationen von $55,5 \%$ bis $88,8 \%$ (A1) und von $72,7 \%$ bis $88,8 \%$ (A2). Davon ausgehend reicht die Differenz zwischen den ersten und den zweiten Einzelbewertungen von $-4,5 \%$ bis $22,2 \%$, was die positive Änderung von 5,9\% ausmacht. Im Vergleich zu den überdurchschnittlichen teilnehmenden Schülern liegt bei den teilnehmenden Schülern mit durchschnittlichen Leistungen die Spannweite der richtig produzierten, zu analysierenden fonetischen Phänomene von $27,7 \%$ bis $100 \%$ (A1) und von $55,5 \%$ bis $100 \%$ (A2), was eine

angezeigt. Somit werden drei leistungsstarke Schüler, fünfzehn Schüler mit durchschnittlichen Leistungen und drei leistungsschwache Schüler in den Tabellen $1-4$ aufgelistet.

${ }^{9}$ Die dritte Möglichkeit zur Klassifizierung der korrekt ausgesprochenen Laute und Lautkombinationen widmet sich einer Rangordnung. Diese Differenzierung nach Rängen ergibt sich aus der Gesamtanzahl in Prozentpunkten von richtig ausgesprochenen Lauten und Lautkombinationen, die relevant für diese Studie sind. Somit wird die Aussprachekompetenz der teilnehmenden Schüler in der Rangstufe „sehr gut“, „gut“, „teilweise“ oder ,wenig“ angezeigt, je nachdem, ob sie jeweils $100-89,1 \%, 89-74,1 \%, 74 \%-49,1 \%$ oder $49-0 \%$ der zu analysierenden Laute und Lautkombinationen aus ihren Sprechrollen und Textabschnitten korrekt artikuliert haben. 
Verbesserung von 11,8\% ausmacht. Aus diesen Ergebnissen geht überdies hervor, dass der Anteil von Lauten und Lautkombinationen sich auf die zielsprachliche Aussprache bei den betreffenden Schülern nicht negativ auswirkt. So legt man den Fokus auf die Ergebnisse der ersten drei durchschnittlichen Schüler, welche am meisten Laute und Lautverbindungen artikuliert haben, liegen die richtig ausgesprochenen, zu untersuchenden fonetischen Phänomene in A2 durchschnittlich bei 77\%, während der Anteil der richtig artikulierten Laute und Lautkombinationen in A1 sich im Mittel auf knapp 59,9\% beläuft. Darüber hinaus ergibt sich die einzige negative Änderung von $-8,4 \%$ zwischen den ersten und den zweiten Einzelbewertungen bei einem durchschnittlichen Schüler aus einer niedrigen Anzahl (12) von auszusprechenden Lauten und Lautkombinationen. Bezüglich der Ergebnisse bei den leistungsschwachen Schülern ergibt sich im Mittel eine Spannweite der korrekt artikulierten Laute und Lautkombinationen von $50 \%$ bis $72,7 \%$ (A1) und von $75 \%$ bis $82 \%$ (A2). Davon ausgehend reicht die Differenz zwischen den ersten und den zweiten Einzelbewertungen von $9,1 \%$ bis $25 \%$, was die beste Änderung von 17,2\% angibt. Wie bei den überdurchschnittlich bewerteten Schülern ist in diesem Zusammenhang festzustellen, dass der Anteil der auszusprechenden Laute und Lautkombinationen keine negative Wirkung auf die zielsprachliche Aussprache unterdurchschnittlich eingestufter Schüler ausübt. Ein gutes Beispiel dafür sind die Ergebnisse des leistungsschwachen Schülers, welcher am meisten Laute und Lautverbindungen artikuliert hat. Bei ihm reicht der Anteil von korrekt produzierten, zu analysierenden Lauten und Lautkombinationen in A2 bei 82,6\%, während der Anteil der betreffenden phonetischen Phänomene in A1 65,2\% beträgt.

Aus Tabelle 2 lässt sich ersehen, wie die leistungsschwachen Schüler die beste Entwicklung bei der zielsprachlichen Aussprache in Bezug auf die zu analysierenden Laute und Lautkombinationen gemacht haben. Während die Änderung zwischen den ersten und den zweiten Einzelbewertungen bei den leistungsstarken Schülern im Mittel bei 5,9\% liegt, beläuft sich diese Rate bei den leistungsschwachen Schülern auf 17,2\%. Hingegen beträgt die durchschnittliche Differenz zwischen den Ergebnissen in A1 und diejenigen in A2 bei den Schülern mit durchschnittlichen Leistungen 11,8\%. Trotz dieser prozentualen Unterschiede ist unverkennbar, dass es jeweiligen Schülern gelungen ist, eine gute Aussprachekompetenz in A2 bezüglich der zu analysierenden deutschen Laute und Lautkombinationen zu erreichen. 


\section{Nordic Journal of Modern Language Methodology}

2019, 7 (1), 165-220 (Part B - Not peer reviewed)

In Tabelle 3 finden sich die Ergebnisse für die dritte Audioaufnahme eines völlig unbekannten Textes, welcher abschnittweise vorgelesen wird. Im Mittel ergibt sich für die leistungsstarken Schüler eine Spannweite der korrekt ausgesprochenen, zu analysierenden Laute und Lautkombinationen von $72 \%$ bis $87,5 \%$. Im Vergleich zu den überdurchschnittlichen teilnehmenden Schülern liegt bei den teilnehmenden Schülern mit durchschnittlichen Leistungen die Spannweite der richtig ausgesprochenen fonetischen Phänomene von 37,9\% bis 100\%. Bezüglich der Ergebnisse bei den leistungsschwachen Schülern ergibt sich im Mittel eine Spannweite der korrekt ausgesprochenen Laute und Lautkombinationen von 54,1\% bis 76,1\%. Wie bei den oben erwähnten Ergebnissen ist hier festzustellen, dass der Anteil von Lauten und Lautkombinationen keine negative Wirkung auf die zielsprachliche Aussprache hat. Ein gutes Beispiel dafür sind die Ergebnisse jener Schüler, die eine hohe Anzahl von zu analysierenden Lauten und Lautverbindungen produziert haben. Bei ihnen reicht die Spannweite der korrekt ausgesprochenen fonetischen Phänomene von 54,1\% bis 83,3\%, was im Mittel eine positive Änderung zwischen A1 und A3 von $12,8 \%$ angibt. $\mathrm{Zu}$ erwähnen ist hier die einzige Ausnahme, und zwar die negative Änderung von $-16 \%$ zwischen den ersten und den dritten Einzelbewertungen bei einem durchschnittlichen Schüler, welchem die höchste Anzahl (47) von zu analysierenden Lauten und Lautkombinationen zugewiesen wird.

Im Gegensatz zu Tabelle 2 geht aus Tabelle 4 deutlich hervor, wie die durchschnittlichen Schüler die beste Entwicklung bei der zielsprachlichen Aussprache in Bezug auf die zu analysierenden Laute und Lautkombinationen zwischen A1 und A3 gemacht haben. Während die Änderung zwischen den ersten und den dritten Einzelbewertungen bei den leistungsschwachen Schülern im Mittel bei 4,5\% liegt, beträgt diese Rate bei den durchschnittlichen Schülern 7,5\%. Hingegen beläuft sich die durchschnittliche Differenz zwischen den Ergebnissen in A1 und diejenigen in A3 bei den leistungsstarken Schülern auf 4,9\%. Es ist ferner festzustellen, dass sowohl die leistungsstarken Schüler wie auch die Schüler mit durchschnittlichen Leistungen eine gute Aussprachekompetenz in A3 bezüglich der zu analysierenden deutschen Laute und Lautkombinationen erzielt haben. Im Unterschied dazu ist es den leistungsschwachen Schülern gelungen, die zu untersuchenden fonetischen Phänomene nur teilweise korrekt zu produzieren. 


\section{Nordic Journal of Modern Language Methodology}

2019, 7 (1), 165-220 (Part B - Not peer reviewed)

\begin{tabular}{|c|c|c|c|c|c|c|c|c|}
\hline \multirow[t]{2}{*}{$\begin{array}{l}\text { Schüler } \\
\text { (S) }\end{array}$} & \multirow{2}{*}{$\begin{array}{l}\text { Laute } \\
\text { /ts/-/ks//z/-/s/ } \\
\text { /f/-/ç/-/x/ }\end{array}$} & \multicolumn{3}{|c|}{$\begin{array}{l}\text { Audioaufnahme } 1 \text { (A1) } \\
\text { (01.06.2016) }\end{array}$} & \multicolumn{3}{|c|}{$\begin{array}{l}\text { Audioaufnahme } 2 \text { (A2) } \\
(08.06 .2016)\end{array}$} & \multirow[t]{2}{*}{ Änderung (\%) } \\
\hline & & $\begin{array}{l}\text { richtig } \\
\text { ausgesprochen }\end{array}$ & $\begin{array}{l}\text { korrekt } \\
(\%)\end{array}$ & Rang & $\begin{array}{l}\text { richtig } \\
\text { ausgesprochen }\end{array}$ & $\begin{array}{l}\text { korrekt } \\
(\%)\end{array}$ & Rang & \\
\hline 1 & 18 & 10 & 55,5 & teilweise & 14 & 77,7 & gut & $+22,2$ \\
\hline 4 & 22 & 17 & 77,2 & gut & 16 & 72,7 & teilweise & $-4,5$ \\
\hline 11 & 9 & 8 & 88,8 & gut & 8 & 88,8 & gut & 0 \\
\hline 2 & 37 & 23 & 62,1 & teilweise & 29 & 78,3 & gut & $+16,2$ \\
\hline 3 & 5 & 4 & 80 & gut & 5 & 100 & sehr gut & +20 \\
\hline 6 & 53 & 28 & 52,8 & teilweise & 41 & 77,3 & gut & $+24,5$ \\
\hline 7 & 50 & 42 & 84 & gut & 45 & 90 & sehr gut & +6 \\
\hline 9 & 15 & 13 & 86,6 & gut & 13 & 86,6 & gut & 0 \\
\hline 10 & 25 & 21 & 84 & gut & 23 & 92 & sehr gut & +8 \\
\hline 12 & 18 & 5 & 27,7 & wenig & 10 & 55,5 & teilweise & $+27,8$ \\
\hline 13 & 5 & 2 & 40 & wenig & 3 & 60 & teilweise & +20 \\
\hline 15 & 14 & 7 & 50 & teilweise & 11 & 78,5 & gut & $+28,5$ \\
\hline 16 & 12 & 9 & 75 & gut & 8 & 66,6 & teilweise & $-8,4$ \\
\hline 17 & 20 & 14 & 70 & teilweise & 14 & 70 & teilweise & 0 \\
\hline 18 & 82 & 58 & 70,7 & teilweise & 65 & 79,2 & gut & $+8,5$ \\
\hline 19 & 2 & 2 & 100 & sehr gut & 2 & 100 & sehr gut & 0 \\
\hline 22 & 55 & 31 & 56,3 & teilweise & 41 & 74,5 & gut & $+18,2$ \\
\hline 23 & 40 & 31 & 77,5 & gut & 34 & 85 & gut & $+7,5$ \\
\hline 5 & 11 & 8 & 72,7 & teilweise & 9 & 81,8 & gut & $+9,1$ \\
\hline 8 & 4 & 2 & 50 & teilweise & 3 & 75 & gut & +25 \\
\hline 14 & 23 & 15 & 65,2 & teilweise & 19 & 82,6 & gut & $+17,4$ \\
\hline
\end{tabular}

Tabelle 1: Audioaufnahmen $1-2$

\begin{tabular}{|c|c|c|c|c|c|}
\hline \multirow[t]{2}{*}{ Schülereinstufung } & \multicolumn{2}{|l|}{$\begin{array}{l}\text { A1 } \\
(01.06 .2016)\end{array}$} & \multicolumn{2}{|l|}{$\begin{array}{l}A 2 \\
(08.06 .2016)\end{array}$} & \multirow[t]{2}{*}{ Änderung (\%) } \\
\hline & korrekt (\%) & Rang & korrekt (\%) & Rang & \\
\hline überdurchschnittlich $(\mathrm{n}=3)$ & 73,8 & teilweise & 79,7 & gut & $+5,9$ \\
\hline durchschnittlich $(\mathrm{n}=15)$ & 67,7 & teilweise & 79,5 & gut & $+11,8$ \\
\hline unterdurchschnittlich $(\mathrm{n}=3)$ & 62,6 & teilweise & 79,8 & gut & $+17,2$ \\
\hline
\end{tabular}

Tabelle 2: Änderung nach Schülereinstufung zwischen A1 - A2 


\section{Nordic Journal of Modern Language Methodology}

2019, 7 (1), 165-220 (Part B - Not peer reviewed)

\begin{tabular}{|c|c|c|c|c|c|}
\hline \multirow[t]{2}{*}{$\begin{array}{l}\text { Schüler } \\
\text { (S) }\end{array}$} & \multirow{2}{*}{$\begin{array}{l}\text { Laute } \\
/ \text { ts } /-/ \mathbf{k s} / / \mathbf{z} /-/ \mathrm{s} / / \mathrm{g} /- \\
/ \mathrm{ç} /-/ \mathbf{x} /\end{array}$} & \multicolumn{3}{|c|}{$\begin{array}{l}\text { Audioaufnahme } 3 \text { (A3) } \\
(15.06 .2016)\end{array}$} & \multirow{2}{*}{$\begin{array}{l}\text { Änderung } \\
\text { A1 } \rightarrow \text { A3 } \\
(\%)\end{array}$} \\
\hline & & $\begin{array}{l}\text { richtig } \\
\text { ausgesprochen }\end{array}$ & $\begin{array}{l}\text { korrekt } \\
(\%)\end{array}$ & Rang & \\
\hline 1 & 30 & 23 & 76,6 & gut & $+21,1$ \\
\hline 4 & 25 & 18 & 72 & teilweise & $-5,2$ \\
\hline 11 & 8 & 7 & 87,5 & gut & $-1,3$ \\
\hline 2 & 6 & 5 & 83,3 & gut & $+21,2$ \\
\hline 3 & 16 & 13 & 81,2 & gut & $+1,2$ \\
\hline 6 & 17 & 10 & 58,8 & teilweise & +6 \\
\hline 7 & 14 & 9 & 64,2 & teilweise & $-19,8$ \\
\hline 9 & 24 & 18 & 75 & gut & $-11,6$ \\
\hline 10 & 47 & 32 & 68 & teilweise & -16 \\
\hline 12 & 29 & 11 & 37,9 & wenig & $+10,2$ \\
\hline 13 & 6 & 6 & 100 & sehr gut & +60 \\
\hline 15 & 15 & 11 & 73,3 & teilweise & $+23,3$ \\
\hline 16 & 23 & 19 & 82,6 & gut & $+7,6$ \\
\hline 17 & 30 & 25 & 83,3 & gut & $+13,3$ \\
\hline 18 & 14 & 13 & 92,8 & sehr gut & $+22,5$ \\
\hline 19 & 22 & 17 & 77,2 & gut & -22.8 \\
\hline 22 & 8 & 6 & 75 & gut & $+18,7$ \\
\hline 23 & 21 & 16 & 76,1 & gut & $-1,4$ \\
\hline 5 & 21 & 16 & 76,1 & gut & $+3,4$ \\
\hline 8 & 24 & 13 & 54,1 & teilweise & $+4,1$ \\
\hline 14 & 7 & 5 & 71,2 & teilweise & +6 \\
\hline
\end{tabular}

Tabelle 3: Audioaufnahme 3

\begin{tabular}{|l|l|l|l|l|l|}
\hline Schülereinstufung & \multicolumn{2}{|l|}{$\begin{array}{l}\text { A1 } \\
(\mathbf{0 1 . 0 6 . 2 0 1 6 )}\end{array}$} & $\begin{array}{l}\text { A3 } \\
(\mathbf{1 5 . 0 6 . 2 0 1 6 )}\end{array}$ & Änderung (\%) \\
\cline { 2 - 6 } & korrekt (\%) & Rang & korrekt (\%) & Rang \\
\hline überdurchschnittlich (n=3) & 73,8 & teilweise & 78,7 & gut & $\mathbf{+ 4 , 9}$ \\
\hline durchschnittlich (n=15) & & & & gut & $\mathbf{+ 7 , 5}$ \\
\hline unterdurchschnittlich (n=3) & 67,7 & teilweise & 75,2 & & \\
& & & & teilweise & $\mathbf{+ 4 , 5}$ \\
\hline
\end{tabular}

Tabelle 4: Änderung nach Schülereinstufung zwischen A1 - A3 


\section{Nordic Journal of Modern Language Methodology}

2019, 7 (1), 165-220 (Part B - Not peer reviewed)

\subsubsection{Ein Follow-up-Schüler-Fragebogen}

Neben den bereits dargestellten Audioaufnahmen wird die schriftliche Befragung in Form von einem Fragebogen als quantitatives Untersuchungsinstrument gewählt. Der schriftlich zugestellte Fragebogen besteht aus acht Fragen, welche in kürzerer Zeit auf der Lernplattform ItsLearning beantwortet werden. Die vorliegende Befragung wird von allen teilnehmenden Schülern nach der Uraufführung der Tierfabeln freiwillig und anonym durchgeführt und lässt sich als offen und standarisiert verstehen (vgl. Albert et al., 2014, S. 67). Dies bedeutet einerseits, dass die meisten Antworten völlig selbstständig formuliert und erst bei der späteren Auswertung bestimmten Kategorien zugeordnet werden. Andererseits werden die Befragten mit einer Frage außerdem dazu aufgefordert, aus bestimmten Antwortmöglichkeiten ihre Antwort auszuwählen. Dabei wird überdies die sogenannte Likertskala genutzt, denn die Befragten werden zu einer bestimmten Aussage gebeten, ihre eigene Einschätzung einzubringen (vgl. Passon, 2014, S. 118, in Anlehnung an Zoltan Dörnyei), und zwar: „Wenn auf einer Skala 6 das Beste und 0 das Schlechteste ist, wie schätzt Du Deine mündlichen Sprachfertigkeiten zu Beginn des Theaterprojekts und am Ende des Theaterprojekts ein?“ Diese leicht zu beantwortende geschlossene Frage wird zu Beginn der Befragung als Einleitung zugestellt, damit die Befragten sich an dem Kontext des Fragebogens orientieren. Außerdem werden alle vorgegebenen Einträge nach einem typisierenden und einem skalierenden Schema sortiert. Dies heißt, dass den Äußerungen der Befragten keine oder eine negative, eine positive oder mehr als eine positive Typisierung, aus welcher jeweils keine, eine (schwache) positive oder eine starke positive Änderung resultiert, zugeschrieben wird.

Bei der Datenauswertung zeigten sich die acht Fragen des Fragebogens für die Beantwortung der Forschungsfrage nach den Auswirkungen von Drama- und Theaterpädagogik sowohl auf fachbezogene wie auch auf fachübergreifende Lernziele relevant. Sämtliche Fragen gehören zu einer Kategorie, welche auf das Fach Deutsch II (Kategorie 1 - Verstehen und Sprechen, Kategorie 3 -Allgemeine Sprachfertigkeiten, Kategorie 4 - Vorteile Deutsch durch Dramapädagogik zu lernen, Kategorie 7 - Aussprache) oder auf ein interdisziplinäres Fachgebiet (Kategorie 2 - Motivation, Kategorie 5 Performanz, Kategorie 6 - Literarische Kompetenz, Kategorie 8 - Persönliche Haltung gegenüber dem Theaterprojekt) gerichtet ist. 


\section{Nordic Journal of Modern Language Methodology}

Was das Verstehen und Sprechen ${ }^{10}$ sowie die Allgemeinen Sprachfertigkeiten ${ }^{11}$ angeht, äußerten sich jeweils $46 \%$ und $75 \%$ der Befragten stark positiv (s. Abbildung 3 und Abbildung 5). Die meisten Äußerungen hoben hervor, dass man am Ende des Theaterprojekts den eigenen Wortschatz erweitern, sich der Artikulation schwer auszusprechender Laute und Lautverbindungen bewusstmachen, die bereits vorhandenen grammatischen Kenntnisse festigen sowie das Leseverstehen, die Aussprache und die Satzmelodie in der Zielsprache verbessern konnte. Bezüglich des interdisziplinären Lernziels der Performanz ${ }^{12}$ sprachen sich 9 von 17 durchschnittlich bewerteten Befragten und 2 von 3 leistungsschwach eingestuften Befragten jeweils positiv und stark positiv für die Überwindung von Lampenfieber und Redeangst durch Theaterspielen (s. Abbildung 7). Neben den klaren Vorteilen des Umgangs mit Fabeldichtung ${ }^{13}$ im vorliegenden Theaterprojekt (s. Kapitel 2, Abschnitt 3), betonten $79 \%$ der Befragten (s. Abbildung 9) überdies individuelle Eigenschaften, Persönlichkeitsmerkmale und Einstellungen wobei soziale Kompetenzen wie Zusammenarbeit und Kooperation, persönlich bezogene Kompetenzen wie Selbstvertrauen und Zufriedenheit und der Spielfaktor vorrangig waren ${ }^{14}$.

Wie sich das Theaterprojekt mit dramatischen Tierfabeln auf die persönliche Haltung der teilnehmenden Schüler zum Deutschlernen ausgewirkt hat ${ }^{15}$, lässt sich in den inhaltlichen Ergebnissen der Kategorie 4 zeigen: Über 50\% der Befragten sprachen sich für eine starke positive Änderung aus, während nur $13 \%$ auf keine Änderung hindeuteten (s. Abbildung 6).

Überraschenderweise geht aus den inhaltlichen Ergebnissen des Fragebogens sowie aus den in Kapitel 4.1 dargestellten Audioaufnahmen hervor, dass die Lernmotivation der teilnehmenden Schüler keine Voraussetzung für ein erfolgreiches Lernen ist ${ }^{16}$. Dies spiegelt sich in der Bewertung mündlicher Leistungen bei 3 von 6 unmotivierten Befragten mit

\footnotetext{
${ }^{10}$ Frage 1: „Wenn auf einer Skala 6 das Beste und 0 das Schlechteste ist, wie schätzt Du Deine mündlichen Sprachfertigkeiten zu Beginn des Theaterprojekts und am Ende des Theaterprojekts ein?“

${ }^{11}$ Frage 3: „Hat Deine Erfahrung mit diesem Theaterprojekt Deine Deutschkenntnisse positiv beeinflusst? (z.B. Wortschatz, Aussprache, Inhalt, Strategien, Verständlichkeit, Grammatik...) Wenn ja, wie?“

12 Frage 5: „Hat die Aufführung einer Fabel Dir dazu verholfen, vor einem Publikum zu sprechen? Wenn ja, warum?"

${ }^{13}$ Frage 6: „Welche Unterschiede hätte es gemacht, wenn wir statt einer Fabel ein klassisches Drama gespielt hätten?"“

${ }^{14}$ Frage 8: „Was hat Dir an der Arbeit mit einer Fabel am besten gefallen?“

15 Frage 4: „Siehst Du Vorteile, eine Fremdsprache auch durch ein deutschsprachiges Theaterstück zu lernen? Wenn ja, welche?"

${ }^{16}$ Frage 2: „Hat sich Deine Teilnahme am Theaterprojekt auf Deine Motivation Deutsch zu sprechen, ausgewirkt? Wenn ja, wie?“
} 


\section{Nordic Journal of Modern Language Methodology}

2019, 7 (1), 165-220 (Part B - Not peer reviewed)

durchschnittlichen Leistungen wider: Trotz geringer Leistungsmotivation gelang es ihnen, die Aussprache der zu analysierenden Laute und Lautkombinationen am Ende des Theaterprojekts stark zu verbessern (s. Abbildung 4). Hingegen lässt sich aus den Ergebnissen für die dritte Audioaufnahme ersehen, dass die mündlichen Leistungen bei 2 von 6 stark motivierten Schülern entweder stagnierten oder sich verschlechterten.

Was die Bewertung des eigenen, d.h. durch den jeweiligen Schüler selbst geschätzten, phonetischen Leistungsniveaus anbelangt (s. Abbildung 8), kann man zusammenfassend festhalten, dass die Selbsteinschätzungen oft nicht mit dem gemessenen Leistungsniveau übereinstimmen ${ }^{17}$. Dies lässt sich vor allem an zwei Beispielen gut belegen: Zwar erkannten 8\% der Befragten keine Änderung in ihrer zielsprachlichen Aussprache, doch gelang es ihnen in der dritten Audioaufnahme, die zu analysierenden Laute und Lautkombinationen gut/sehr gut zu artikulieren. Im Gegensatz dazu entsprachen nur 19\% von 63\% der starken positiven Einschätzungen einer realen sehr guten mündlichen Produktion dieser schwer auszusprechenden Zischlaute und Lautverbindungen.

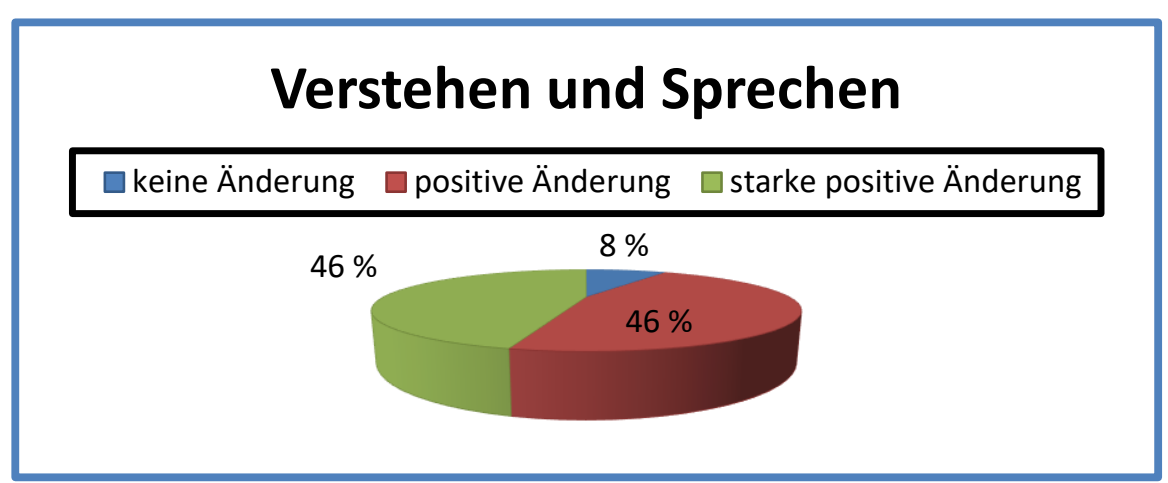

Abb. 3: Kategorie 1 - Verstehen und Sprechen

\footnotetext{
17 Frage 7: „Fällt es Dir jetzt leichter, Laute wie „Mädchen“ /ç/, „auch“ /x/, „Sprache“ $/ \mathrm{J} /$, „Salat“ /Z/ auszusprechen?"
} 


\section{Nordic Journal of Modern Language Methodology}

\section{9, 7 (1), 165-220 (Part B - Not peer reviewed)}

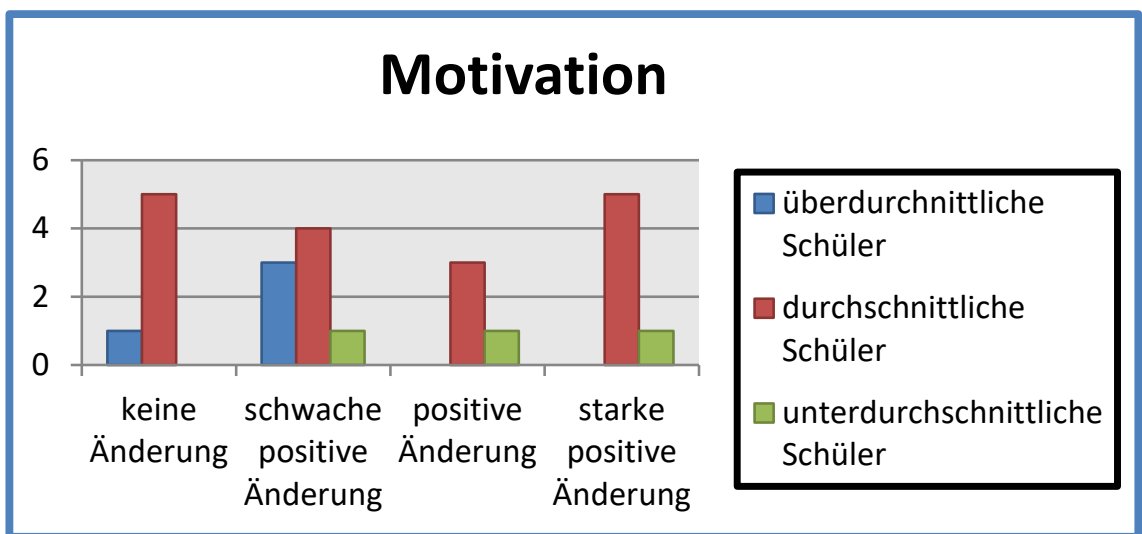

Abb. 4: Kategorie 2-Motivation

\section{Allgemeine Sprachfertigkeiten}

$\square$ keine Änderung $\square$ positive Änderung $\square$ starke positive Änderung

$4 \%$

$21 \%$

$75 \%$

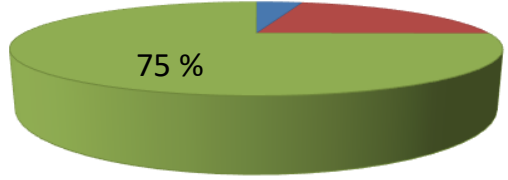

Abb. 5: Kategorie 3 - Allgemeine Sprachfertigkeiten

\section{Vorteile Deutsch durch Dramapädagogik zu lernen}

$\square$ keine Änderung $\square$ positive Änderung $\square$ starke positive Änderung

$13 \%$

$29 \%$

$58 \%$

Abb. 6: Kategorie 4 - Vorteile Deutsch durch Dramapädagogik zu lernen 


\section{Nordic Journal of Modern Language Methodology}

\section{9, 7 (1), 165-220 (Part B - Not peer reviewed)}

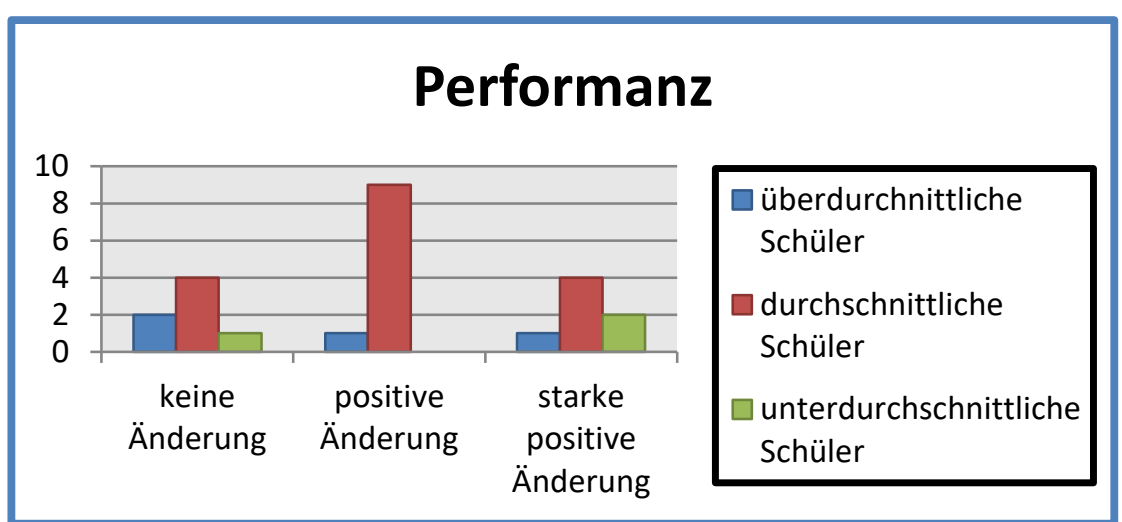

Abb. 7: Kategorie 5 - Performanz

\section{Aussprache}

$\square$ keine Änderung $\square$ positive Änderung $\square$ starke positive Änderung

$8 \%$ $29 \%$

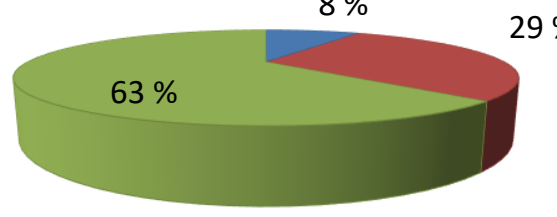

Abb. 8: Kategorie 7 - Aussprache

\section{Persönliche Haltung gegenüber dem Theaterprojekt}

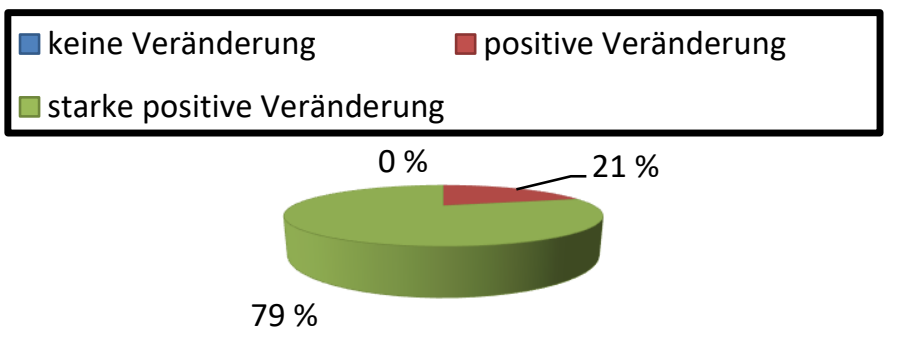

Abb. 9: Kategorie 8 - Persönliche Haltung gegenüber dem Theaterprojekt 


\section{Nordic Journal of Modern Language Methodology}

2019, 7 (1), 165-220 (Part B - Not peer reviewed)

\section{Ausblick}

Wie aus der Durchführung des vorliegenden Theaterprojektes deutlich geworden ist, lassen sich abschließend zwei Desiderate formulieren: Zum einen ist in den neueren Deutschlehrbüchern auf dem Niveau II für die erste Klasse in der Sekundarstufe II eine Vielfalt an authentischen literarischen Textsorten in der Zielsprache sowie an Unterrichtsmethoden wünschenswert. Diese Fülle von Unterrichtsmaterialien sollte auch Dramentexten verschiedener Untergattungen, wie z. B. Tierfabeln, Sketchen oder Improvisationstheaterstücken, drama- und theaterpädagogischen Einsätzen den Vorrang geben.

Zum anderen ist es zudem angebracht, dass es sowohl in den norwegischen Lehrplänen für die Fremdsprache Deutsch II wie auch in den Richtlinien zum norwegischen Abitur in diesem Fach nicht nur für fachorientierte Fremdsprachenkompetenzen, sondern auch für Selbst- und Methodenkompetenzen wie Aussprache, Performanz, Kreativität und Lernstrategien Platz gibt. Fokussiert man die Lernkompetenzen, bedarf es außerdem des Erstellens von unterrichtlichen Lehr- und Lernsituationen, in denen die Schüler die darauf aufbauenden fachlichen Kompetenzen erarbeiten können. In diesem Zusammenhang erweist sich eine formative bzw. prozessnahe Beurteilung als ein Werkzeug zu einer solchen Ausrichtung eines kompetenzorientierten Fremdsprachenunterrichts. Mittels lernförderlicher Rückmeldungen kann die Lehrperson individuelle Lernlücken diagnostizieren und folglich den Lernenden ihre realen fachlichen Defizite bewusstmachen. In diesem Sinne gilt die formative Beurteilung als eine Ausgangslage für einen transparenten Fremdsprachenunterricht, in dem es den Schülern ermöglicht wird, einzelne Aufgabenbereiche zu bewältigen und die eigenen Wege zum Fremdsprachenlernen zu entdecken. Letztendlich kann den Lernenden eine derartige aktive Rollenübernahme in der Zielsprache zu einer größeren Kontrolle ihres Lernprozesses sowie zum Verständnis der eigenen Lernschwierigkeiten verhelfen und somit Anlass zur Motivierung geben (vgl. Düwell, 1998, S. 41). 


\section{Literaturverzeichnis}

\section{Primärliteratur}

Bjørke, C.; Eckhardt, H.-J.; Handeland, K.; Karnland, A.; Lysaker, M; Odeldahl, A. (2. Auflage, 2012). Einfach Deutsch 1. Oslo: Gyldendal.

Finsvik Andersen, E. \& Bali, B. (2. Auflage 2012). Ankunft 1. Oslo: Cappelen Damm.

Heuser, O. (2016a). Märchen und Geschichten von und mit Tieren. 14 Lesetheaterstücke. Abrufdatum 04.10.2016. Verfügbar unter: http://www.mopkaratz.com/lesetheater/

Heuser, O. (2016b). Tierfabeln aus aller Welt. 9 Lesetheaterstücke +2 vereinfachte Stücke für DaF/Z. Abrufdatum 04.10.2016. Verfügbar unter: http://www.mopkaratz.com/lesetheater/

Nygård, T., Skorge; K., Halvor, Th. \& Biesalski, P. (2012). Weitblick 2. [Ort ungenannt]: Aschehoug.

Rug, W. (2012). 77 Klangbilder gesprochenes Hochdeutsch. Übungen, Spiele, Tipps und Tricks zum phonetischen Training Deutsch als Fremdsprache. Sprachniveau B1 bis C2. Leipzig: Schubert.

Schulze, A.-M. (2012). Weiter geht's. Tekst- og arbeidsbok. Oslo: Samlaget.

\section{Sekundärliteratur}

Aschehoug. (2012). Forslag til årsplaner Weitblick 2 - Vg1. Abrufdatum: 22.12.2019.

Verfügbar unter: https://www.aschehoug.no/Undervisning/Verk/Weitblick-2012-2013

Bohn, O.-Sch. (1998). Wahrnehmung fremdsprachlicher Laute: Wo ist das Problem? In: H.

Wegener (Hrsg.), Eine zweite Sprache lernen. Empirische Untersuchungen zum

Zweitspracherwerb (S. 1-20). Tübingen: Gunter Narr.

Dentler, S. (2000). Deutsch und Englisch - das gibt immer Krieg! In: S. Dentler, B. Hufeisen \& B. Lindemann (Hrsg.), Tertiär- und Drittsprachen. Projekte und empirische

Untersuchungen (S. 77-97). Tübingen: Stauffenburg.

Düwell, H. (1998). Motivation und Motivierung im Fremdsprachenunterricht. In: U. O. H. Jung (Hrsg.), Praktische Handreichung für Fremdsprachenlehrer (S. 38-45). Frankfurt am Main: Peter Lang.

Edmondson, W. \& House, J. (2. Auflage 2000). Einführung in die Sprachlehrforschung. Tübingen: Narr Francke Attempto.

Edmondson, W. \& House, J. (4. Auflage 2011). Einführung in die Sprachlehrforschung. Tübingen: Narr Francke Attempto.

Eggesb $\varnothing$ Abrahamsen, J. \& Morland, A. (4. Auflage, 2012). Starthjelp i fonetikk og lingvistikk. Trondheim: Fagbokforlaget.

Elis, F. (2015). Mit dramapädagogischen Methoden sprachliche und kommunikative Kompetenzen fördern. In: W. Hallet \& C. Surkamp (Hrsg.), Dramendidaktik und Dramapädagogik im Fremdsprachenunterricht (S. 89-115). Trier: Wissenschaftlicher Verlag Trier (WVT).

Europarat [Goethe-Institut, KMK, EDK \& BMBWK] (Hrsg.). (2001). Gemeinsamer europäischer Referenzrahmen für Sprachen: lernen, lehren, beurteilen. Berlin et al.: Langenscheidt. 
Nordic Journal of Modern Language Methodology

Ewers, H.-H. (2012). Kinder und Jugendliteratur - Begriffsdefinitionen. In: G. Lange (Hrsg.), Kinder- und Jugendliteratur der Gegenwart. Ein Handbuch (S. 3-12). Baltmannsweiler:

Schneider Verlag Hohengehren.

Fabel. (2018). In Deutsches Universalwörterbuch online. Abrufdatum: 13.07.2018. Verfügbar unter: https://www.duden.de/rechtschreibung/Fabel

Funk, H.; Kuhn, Chr.; Skiba, D.; Spaniel-Weise, D. \& Wicke, R. E. (2014). Aufgaben, Übungen, Interaktion. München: Klett-Langenscheidt.

Haas, G. (2003). Aspekte der Kinder- und Jugendliteratur. Genres - Formen und Funktionen - Autoren. Frankfurt am Main: Peter Lang.

Legutke, M. K. (2008). Kommunikative Kompetenz: Von der Übungstypologie für kommunikativen Englischunterricht zur Szenariendidaktik. In: L. Bredella, H. Christ, M. K. Legutke, F.-J. Meißner (Hrsg.), Kommunikative Kompetenz als fremdsprachendidaktische Vision (S. 15- 42). Tübingen: Gunter Narr.

Levy, G. (2013). 111 Theaterspiele. Übungen zum szenischen Spiel für Unterricht, AGs und Projekte. Mülheim an der Ruhr: Verlag an der Ruhr.

Marx Åberg, A. (2010). Lesefreude und Lernerorientierung. Eine Untersuchung von Lehrerentscheidungen beim Lesen eines Romans in einer Schülergruppe im schwedischen Unterricht Deutsch als Fremdsprache. Växjö: Linnaeus University Press.

Passon, J. (2014). Shakespeare in der Realschule inszenieren. Theatre Education zur Förderung von kommunikativer und performativer Fremdsprachenkompetenz. Berlin: LIT Verlag Dr. W. Hopf.

Reinke, K. \& Hirschfeld, U. (2016). 44 Aussprachespiele. Deutsch als Fremdsprache. Stuttgart: Klett.

Rigotti, E. T. (2010). Kommunikative Kompetenz im Fremdsprachenunterricht in der Sekundarstufe: Italienisch lernen in Deutschland, Deutsch lernen in Italien. Eine vergleichende Analyse. (Dissertation, Pädagogische Hoschschule Ludwigsburg). Abrufdatum: 15.07.2016. Verfügbar unter: https://phbl-opus.phlb.de/files/28/A_Dissertation.pdf

Steinlein, R. (2004). Kinder- und Jugendliteratur als Schöne Literatur. Gesammelte Aufsätze zu ihrer Geschichte und Ästhetik. Frankfurt am Main: Peter Lang.

Taube, G. (4. Auflage 2005). Kinder und Jugendtheater. In: G. Lange (Hrsg.), Taschenbuch der Kinder- und Jugendliteratur. Band 2 (S. 568-589). Baltmannsweiler: Schneider Verlag Hohengehren.

Utdanningsdirektoratet. (2006). Laereplan i fremmedspråk. Abrufdatum: 16.07.2016.

Verfügbar unter: http://www.udir.no/K106/FSP1-01/Hele/Komplett_visning?read=1\&print=1 


\section{Nordic Journal of Modern Language Methodology}

2019, 7 (1), 165-220 (Part B - Not peer reviewed)

\section{Anhänge}

\section{Probeplan für die Inszenierung von fünf dramatischen Tierfabeln von Olaf Heuser}

\begin{tabular}{|c|c|c|}
\hline Woche 1 (11.05.2016) & Inspiration & $\begin{array}{l}\text { 1. Unterrichtsstunde (US): Szenische } \\
\text { Improvisation }\end{array}$ \\
\hline Woche 2 (18.05.2016) & & $\begin{array}{l}\text { 2. US: Körperwahrnehmung und } \\
\text { Körpersprache }\end{array}$ \\
\hline \multirow[t]{2}{*}{ Woche 3 (24.05.-25.05.2016) } & & $\begin{array}{l}\text { 3. US: Literarische } \\
\text { Rezeptionskompetenz, } \\
\text { Körperwahrnehmung und } \\
\text { Rollenvergabe (Vorlesen und } \\
\text { Rollenverteilung) }\end{array}$ \\
\hline & $\begin{array}{l}\text { Spielfähigkeit / } \\
\text { Reflexion }\end{array}$ & $\begin{array}{l}\text { 4. US: Vorführung in Kleingruppen mit } \\
\text { Text (Vorlesen) }\end{array}$ \\
\hline \multirow[t]{2}{*}{ Woche 4 (31.05.-01.06.2016) } & & $\begin{array}{l}\text { 5. US: Vorführung vor dem Ensemble } \\
\text { mit Text (Vorlesen) }\end{array}$ \\
\hline & & $\begin{array}{l}\text { 6. US: Vorführung in Kleingruppen mit } \\
\text { Text (Vorlesen und 1. Audioaufnahme } \\
\text { bekannter Rollen) }\end{array}$ \\
\hline \multirow[t]{2}{*}{ Woche 5 (07.06.-08.06.2016) } & & $\begin{array}{l}\text { 7. US: Vorführung in Kleingruppen mit } \\
\text { Text (Vorlesen) und } \\
\text { Aussprachetraining }\end{array}$ \\
\hline & & $\begin{array}{l}\text { 8. US: Generalprobe ohne Text ( } 2 . \\
\text { Audioaufnahme bekannter Rollen) }\end{array}$ \\
\hline \multirow[t]{2}{*}{ Woche $6(14.06 .-15.06 .2016)$} & & $\begin{array}{l}\text { 9. US: Uraufführung mit Souffleur } \\
\text { und/oder Spickzetteln und Reflexion } \\
\text { über das Theaterprojekt }\end{array}$ \\
\hline & Reflexion & $\begin{array}{l}\text { 10. US: Ergebnissicherung des Gelernten } \\
\text { (3. Audioaufnahme unbekannter } \\
\text { Rollen) und Schlussreflexion }\end{array}$ \\
\hline
\end{tabular}




\section{Unterrichtsblöcke}

Erster Unterrichtsblock: Phase der Inspiration

Unterrichtsstunden: 3 US à 90 Minuten (eine fünfminutige Pause inklusive)

\section{Lernziele:}

- $\quad$ einen animierten Stummkurzfilm (Oktapodi, 2007) zum Tonfilm zu legen

- äußerst wichtige grammatische Strukturen (Satzbau, Konjugation im Präsens, Subjekt-Verb-Kongruenz und angemessene Satzverknüpfung) korrekt zu verwenden

- $\quad$ szenische Improvisation und emotionalen Ausdruck zu fördern

- Unlustgefühle und Angst vor dem Sprechen in der Fremdsprache abzubauen

- sich verschiedener Redensarten, gefühlsgeladener Stimmen und der eigenen Körpersprache bewusst zu werden

- einen authentischen Text (Dramatext) zu verstehen

- $\quad$ sich der Merkmale einer Fabel bewusst zu werden

- sich in eine Fabelfigur hineinzuversetzen

- $\quad$ sich gegenseitig ein Theaterstück vorzuführen

Thema: Die Liebe, Leute und Lesezeit (Lektionen 4, 5 und 15 aus Weitblick 2)

\begin{tabular}{|c|c|c|}
\hline \multirow{2}{*}{$\begin{array}{l}\text { Erste } \\
\text { Unterrichtsstunde } \\
(\mathbf{1 1 . 0 5 . 2 0 1 6 )}\end{array}$} & \multicolumn{2}{|c|}{ Vor dem Sehen } \\
\hline & Übung 1 & $\begin{array}{l}\text { Partnerarbeit } \\
\text { Zeit: } 15 \text { Minuten } \\
\text { Die Lerner setzen sich mit der Filmhandlung } \\
\text { auseinander. Dann erstellen sie eine Mindmap zum } \\
\text { Titel des Kurzfilmes Oktapodi }{ }^{18} \text {. Die Mindmaps } \\
\text { werden im Plenum besprochen. Das Thema } \\
\text { Liebesgeschichte wird auch im Plenum } \\
\text { angeschnitten, indem die Lerner sich zum typischen }\end{array}$ \\
\hline
\end{tabular}

\footnotetext{
${ }^{18}$ Darin geht es um einen animierten stummen Kurzfilm über eine außergewöhnliche Liebesgeschichte: Zwei Tintenfische (oder „Oktopusse“) sind extrem ineinander verliebt. Beide leben in einem Aquarium einer Fischerei am Mittelmeer. Aber plötzlich packt der Verkäufer das Weibchen am Hals und verkauft es einem Schlachter. Verblüfft sieht das Männchen, wie seine Geliebte in eine Kiste auf ein Mofa gestellt wird. Es robbt aus dem Aquarium, klettert auf den Roller und hält sich dabei am Steuerrad fest. Dann beginnt eine turbulente Fahrt durch die ganze Stadt bis zum Meer. Als die Verfolgungsjagd zu Ende geht, kommt eine Möwe zu dem Weibchen, fängt es mit ihrem Schnabel und fliegt fort. Ein neues Abenteuer beginnt für das Männchen, welches beschließt, die Verfolgungsjagd wiederaufzunehmen und seine Geliebte zu retten. Dieser stumme Kurzfilm wurde gewählt, weil er sich besonders für die Synchronisation einer Sequenz in der Fremdsprache durch kurze Sätze oder Ausrufe sehrt gut eignet. Darüber hinaus ist der Kurzfilm sehr witzig und wirkt sehr verspielt.
} 


\section{Nordic Journal of Modern Language Methodology}

2019, 7 (1), 165-220 (Part B - Not peer reviewed)

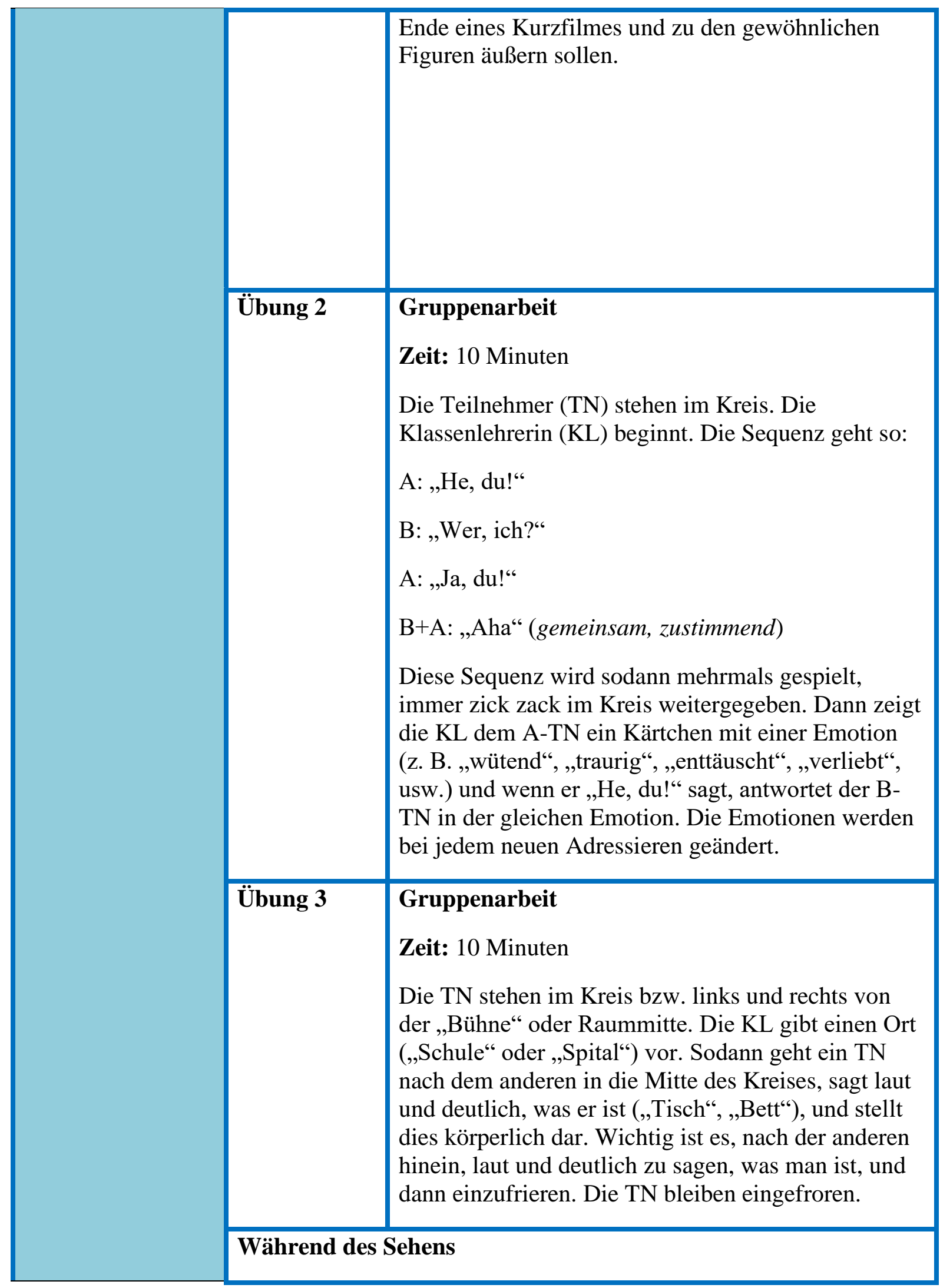


2019, 7 (1), 165-220 (Part B - Not peer reviewed)

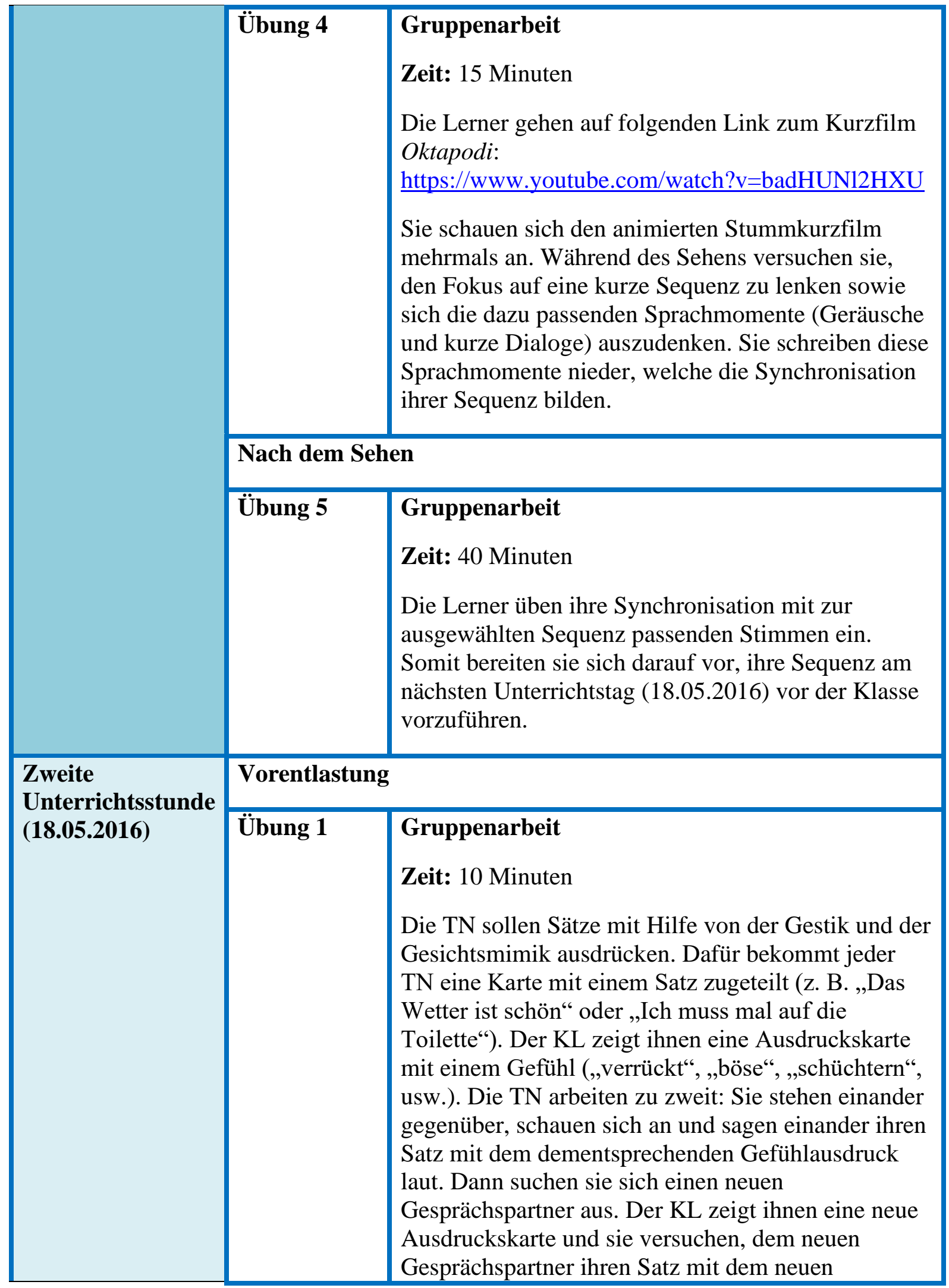




\section{Nordic Journal of Modern Language Methodology}

2019, 7 (1), 165-220 (Part B - Not peer reviewed)

\begin{tabular}{|c|c|c|}
\hline & & $\begin{array}{l}\text { Gefühlausdruck laut zu sagen. Insgesamt werden } \\
\text { zwölf Ausdruckskarten gezeigt. }\end{array}$ \\
\hline & Erarbeitung & \\
\hline & Übung 2 & $\begin{array}{l}\text { Gruppenarbeit } \\
\text { Zeit: } 10 \text { Minuten } \\
\text { Die Lerner üben ihre Synchronisation mit dazu } \\
\text { passenden Stimmen ein. }\end{array}$ \\
\hline & Zielaufgabe & $\begin{array}{l}\text { Gruppenarbeit } \\
\text { Zeit: } 50 \text { Minuten } \\
\text { Die Lerner führen der Klasse ihre Sequenz vor. }\end{array}$ \\
\hline & Reflexion & \\
\hline & Übung 3 & $\begin{array}{l}\text { Gruppenarbeit } \\
\text { Zeit: } 20 \text { Minuten } \\
\text { Folgende Fragen werden zuerst in Gruppen } \\
\text { besprochen: } \\
\text {-Was hat uns am meisten Spaß gemacht? } \\
\text {-Was war das Herausforderndste an der Aufgabe, } \\
\text { aber ist uns am Ende gut gelungen? } \\
\text {-Was war unmöglich zu schaffen/zu } \\
\text { realisieren/durchzuführen? Warum? } \\
\text { Jede Gruppe schreibt ihre Ergebnisse nieder. Dann } \\
\text { werden die Ergebnisse im Plenum } \\
\text { zusammengetragen. Zur Schaffung einer } \\
\text { Gruppenförderung werden die Lerner gebeten, im } \\
\text { großen Kreis zu sitzen. }\end{array}$ \\
\hline Dritte & Vorentlastur & \\
\hline$(24.05 .2016)$ & Übung 1 & $\begin{array}{l}\text { Gruppenarbeit } \\
\text { Zeit: } 15 \text { Minuten } \\
\text { Drei freiwillige TN werden gebeten, auf die „Bühne“ } \\
\text { zu treten. Ein TN zieht ein Kärtchen mit einer } \\
\text { Redensart („Nachrichtensprecher“, „Politikerrede“, }\end{array}$ \\
\hline
\end{tabular}




\begin{tabular}{|c|c|}
\hline & $\begin{array}{l}\text { „Siegerehrung“, usw.) und bekommt einen kurzen } \\
\text { Text zugeteilt. Er liest ihn den anderen zwei TN mit } \\
\text { der dazu passenden Stimmung laut vor. Derselbe } \\
\text { Text wird insgesamt von drei verschiedenen Gruppen } \\
\text { in drei Redensarten vorgelesen. } \\
\text { Nach dem dritten Auftritt werden alle TN gebeten, in } \\
\text { einem Ring zu sitzen und Stellung zu den körperlich } \\
\text { dargestellten Redensarten zu nehmen. Folgende } \\
\text { Fragen werden angegangen: } \\
\text {-Welche Redensart scheint euch am einfachsten / am } \\
\text { schwierigsten vorzuführen? Warum? }\end{array}$ \\
\hline Übung 2 & $\begin{array}{l}\text { Gruppenarbeit } \\
\text { Zeit: } 20 \text { Minuten } \\
\text { Sechs freiwillige TN werden gebeten, auf die Bühne } \\
\text { zu treten. Der erste TN soll sich vorstellen, er ist ein } \\
\text { Teil einer erfundenen Maschine. Er soll sich auch } \\
\text { überlegen, was dieser Teil macht, und der Vorgang } \\
\text { muss wiederholt werden. Dazu muss er auch ein } \\
\text { passendes Geräusch machen. Er muss immer } \\
\text { weitermachen. Der nächste TN fügt der Maschine } \\
\text { einen weiteren Teil hinzu, von dem er glaubt, dass er } \\
\text { für das Funktionieren wichtig ist. Die Maschine wird } \\
\text { also um so viele Bestandteile erweitert wie auf der } \\
\text { Bühne anwesende TN. } \\
\text { Die Übung wird mit anderen freiwilligen TN noch } \\
\text { einmal durchgespielt. } \\
\text { Am Ende der Übung werden alle Lerner zur } \\
\text { Plenardiskussion aufgefordert. Dabei wird } \\
\text { besprochen, was gut / nicht so gut funktioniert hat. }\end{array}$ \\
\hline \multicolumn{2}{|c|}{ Erarbeitung } \\
\hline Übung 3 & $\begin{array}{l}\text { Partnerarbeit } \\
\text { Zeit: } 30 \text { Minuten } \\
\text { Die Lerner arbeiten zu zweit. Sie bekommen eine } \\
\text { Mindmap mit Stichwörtern zum Thema „Merkmale } \\
\text { einer Fabel“ zugeteilt. Paarweise besprechen sie die } \\
\text { Hauptmerkmale der Gattung „Fabel“: Aufbau (Teile } \\
\text { und Ende), Sprache (Dialoge/Monologe), } \\
\text { Raum/Zeit/Handlung (Orte, Zeitspanne, Handlung) }\end{array}$ \\
\hline
\end{tabular}




\section{Nordic Journal of Modern Language Methodology}

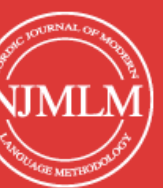

2019, 7 (1), 165-220 (Part B - Not peer reviewed)

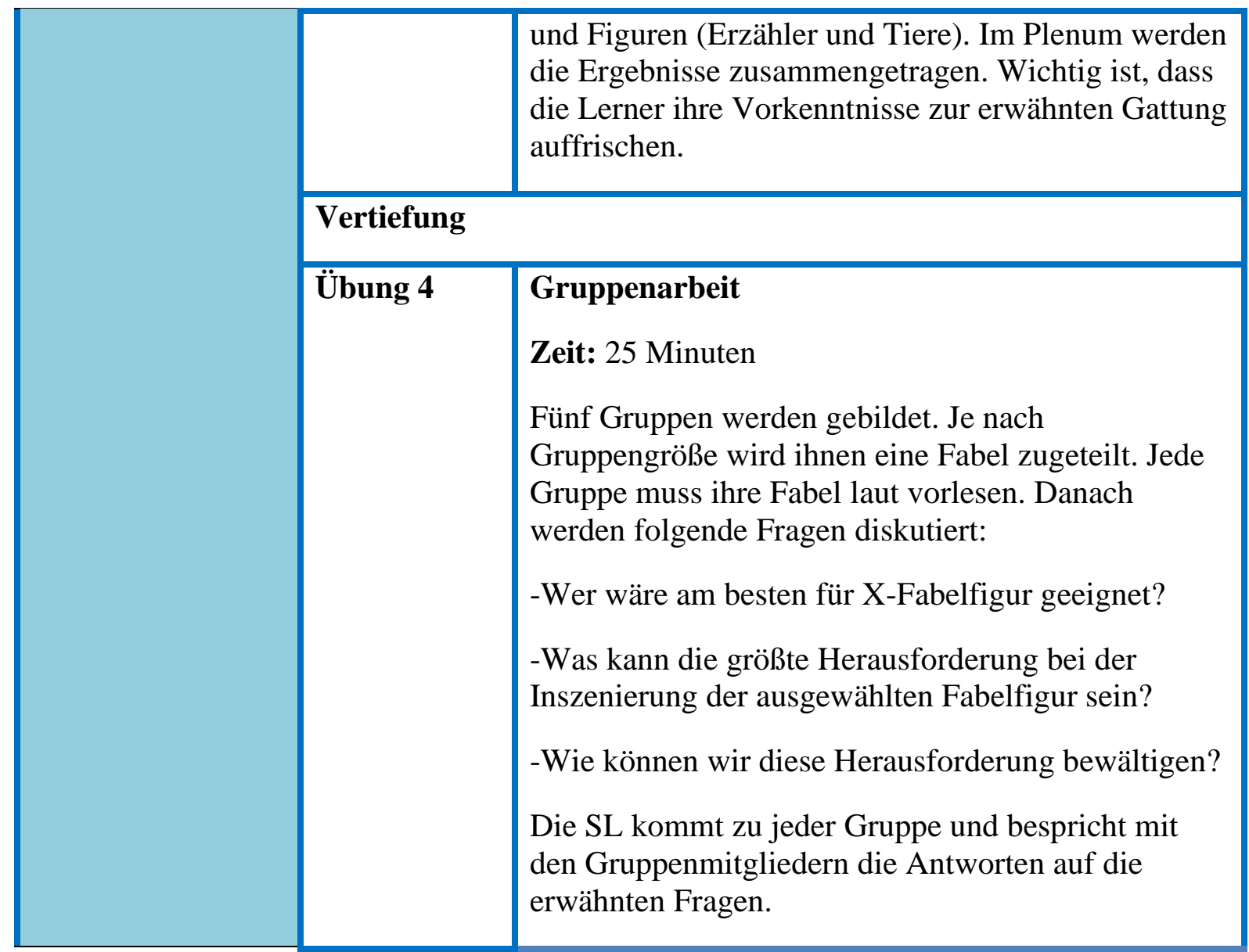

Zweiter Unterrichtsblock: Phase der Spielfähigkeit und Reflexion

Unterrichtsstunden: 6 US à 90 Minuten (eine fünfminutige Pause inklusive)

Lernziele:

- $\quad$ einen authentischen Text (Dramatext) zu verstehen und aufzuführen

- sich in eine Fabelfigur hineinzuversetzen

- das Stimmprofil der Fabelfigur zu entdecken und es an die verkörperte Rollenfigur anzupassen

- das fotografische Gedächtnis zu trainieren

- die eigene Kreativität durch Improvisation auf die Probe zu stellen

- die Körperbeeinflussung zu erlernen und der Reaktionsfähigkeit des Publikums entgegenzukommen

- die Sinne zu schärfen und die persönliche Zufriedenheit durch Teamarbeit zu fördern

- die Fähigkeit zur Übertreibung durch Körpersprache zu begünstigen und dadurch emotionale / körperliche Blockaden zu lösen

- kinästhetisches Bewusstsein für den eigenen Körper zu entwickeln und sich bewusst vor einem Auftritt körperlich zu entspannen 
- $\quad$ sich gegenseitig ein Theaterstück mit /ohne Text vorzuführen

- das Inszenieren mit einer Gruppe zu erlernen

- über die Lernziele eines durchgeführten Theaterprojekts zu reflektieren und schriftlich Stellung dazu zu nehmen

- sich des Unterschieds zwischen wichtigen Zischlauten bewusst zu sein

- wichtige Zischlaute in den Repliken einer Fabelfigur richtig auszusprechen

Thema: Lesezeit (Lektion 15 aus Weitblick 2)

\begin{tabular}{|c|c|c|}
\hline \multirow{8}{*}{\begin{tabular}{|l} 
Vierte \\
Unterrichtsstunde \\
(25.05.2016)
\end{tabular}} & \multicolumn{2}{|c|}{ Vorentlastung } \\
\hline & Übung 1 & Gruppenarbeit \\
\hline & & Zeit: 15 Minuten \\
\hline & & $\begin{array}{l}\text { Die TN sitzen an verschiedenen Stellen } \\
\text { des Klassenzimmers. Sie werden von der } \\
\text { KL dazu aufgefordert, sich gut im Raum } \\
\text { umzuschauen und mentale Fotos von allen } \\
\text { Mitspielern im Raum zu schießen. Ein } \\
\text { Freiwilliger meldet sich. Ihm wird erklärt, } \\
\text { dass sich fünf Mitspieler irgendwo anders } \\
\text { hinsetzen werden, sobald er den Raum } \\
\text { verlässt. Nachdem fünf TN ihre Stühle } \\
\text { verschoben und sich wieder hingesetzt } \\
\text { haben, kann der Freiwillige wieder zurück } \\
\text { ins Klassenzimmer kommen. Sobald er } \\
\text { bereit ist, kann er laut sagen, wer seinen } \\
\text { Platz verschoben hat. Dann heben die fünf } \\
\text { Betreffenden ihre Hände. }\end{array}$ \\
\hline & & $\begin{array}{l}\text { Am Ende des Spiels wird von der KL eine } \\
\text { kurze Diskussion über das Spiel im } \\
\text { Plenum entfacht. Dabei werden folgende } \\
\text { Fragen besprochen: }\end{array}$ \\
\hline & & $\begin{array}{l}\text {-Warum ist es bei diesem Spiel so wichtig, } \\
\text { in Team zu arbeiten? }\end{array}$ \\
\hline & & $\begin{array}{l}\text {-Wie kann dieses Spiel aus der Perspektive } \\
\text { eines Schauspielers sinnvoll/nützlich sein? }\end{array}$ \\
\hline & Übung 2 & $\begin{array}{l}\text { Gruppenarbeit } \\
\text { Zeit: } 15 \text { Minuten }\end{array}$ \\
\hline
\end{tabular}




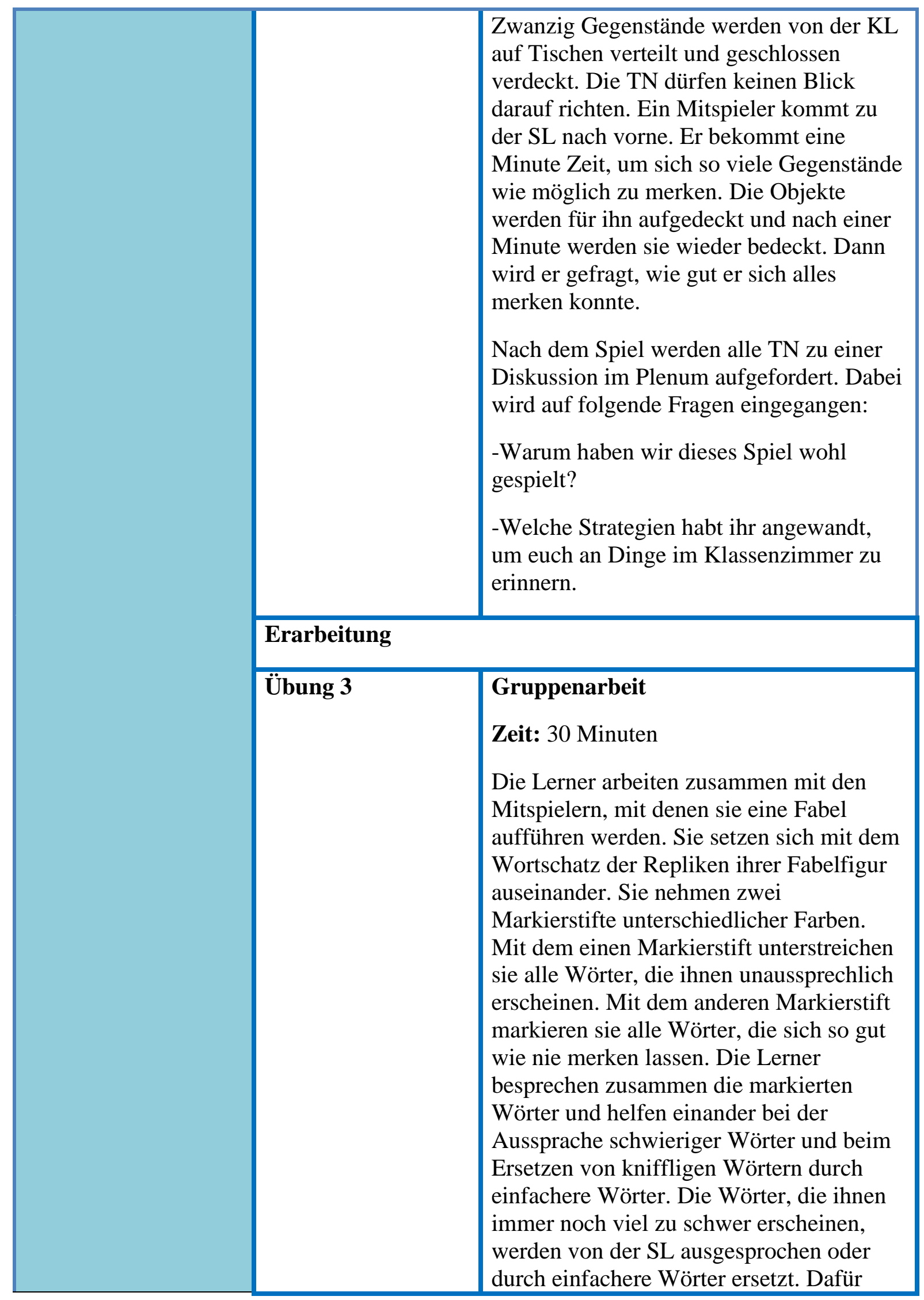




\begin{tabular}{|c|c|c|}
\hline & & $\begin{array}{l}\text { geht die SL im Klassenzimmer herum und } \\
\text { leistet allen Gruppen Hilfe. Die SL } \\
\text { vergewissert sich, dass alle Repliken sich } \\
\text { gut aussprechen und merken lassen. }\end{array}$ \\
\hline & \multicolumn{2}{|c|}{ Vertiefung } \\
\hline & Übung 4 & $\begin{array}{l}\text { Partnerarbeit } \\
\text { Zeit: } 15 \text { Minuten } \\
\text { Die Lerner müssen verschiedene Stimm- } \\
\text { Eigenschaften (Lautstärke, Schnelligkeit, } \\
\text { Tonhöhe, Ausdruck, Grundstimmung und } \\
\text { persönliche Züge) mit verschiedenen } \\
\text { Sätzen aus dem Text ihrer Fabelfigur } \\
\text { ausprobieren. Danach müssen sie } \\
\text { herausfinden, welche Eigenschaften ihnen } \\
\text { am besten zu ihrer Figur gefallen. Die } \\
\text { Übung wird zu zweit gemacht, damit die } \\
\text { TN sich gegenseitig besser helfen können. } \\
\text { Die Ergebnisse werden danach in der } \\
\text { Gruppe zusammengetragen. }\end{array}$ \\
\hline & Übung 5 & $\begin{array}{l}\text { Einzelarbeit } \\
\text { Zeit: } 15 \text { Minuten } \\
\text { Die TN sollen sich ein Kennzeichen für } \\
\text { ihre Fabelfigur einfallen lassen (z. B. } \\
\text { braune Kleider für die Fabelfigur Löwe } \\
\text { oder einen Schnabel aus Pappe für die } \\
\text { Fabelfigur Rabe). Danach sollen sie ihre } \\
\text { Fabelfigur mit angemessener Stimme und } \\
\text { Körpersprache einüben. Am Ende werden } \\
\text { die TN darum gebeten, sich mit ihrer } \\
\text { Fabelfigur gut auszukennen. Hierfür sollen } \\
\text { sie einander ihre Repliken mehrmals } \\
\text { vorlesen. }\end{array}$ \\
\hline \multirow{2}{*}{$\begin{array}{l}\text { Fünfte } \\
\text { Unterrichtsstunde } \\
(\mathbf{3 1 . 0 5 . 2 0 1 6 )}\end{array}$} & \multicolumn{2}{|c|}{ Vorentlastung } \\
\hline & Übung 1 & $\begin{array}{l}\text { Gruppenarbeit } \\
\text { Zeit: } 15 \text { Minuten } \\
\text { Drei Freiwillige (ein Interviewter, ein } \\
\text { Dolmetscher und ein }\end{array}$ \\
\hline
\end{tabular}




\begin{tabular}{|l|l|}
\hline & Nachrichtenmoderator) führen ein \\
Interview. Der Interviewte spricht eine \\
Sprache, die nur er und sein Dolmetscher \\
verstehen. Die Sprache besteht aus \\
Lautkombinationen, die dem Interviewten \\
spontan einfallen. Diese Sprache ist \\
erfunden und hat nichts mit einer \\
wirklichen Sprache zu tun. Der \\
Nachrichtenmoderator stellt klare Fragen \\
auf Deutsch, die der Interviewte in seiner \\
erfundenen Sprache beantwortet. Der \\
Dolmetscher übersetzt die Antworten \\
dermaßen klar und sicher, dass er den \\
Eindruck macht, die Kunstsprache zu \\
beherrschen. Am Ende des Spiels werden \\
folgende Fragen im Plenum besprochen: \\
-Welche Strategien hat der Interviewte \\
verwendet, um seine Rolle zu verkörpern? \\
-Wie hat es dem Dolmetscher gelungen, \\
das Übersetzte interessant darzustellen? \\
-Was hat der Nachrichtenmoderator \\
glaubhaft gemacht?
\end{tabular}




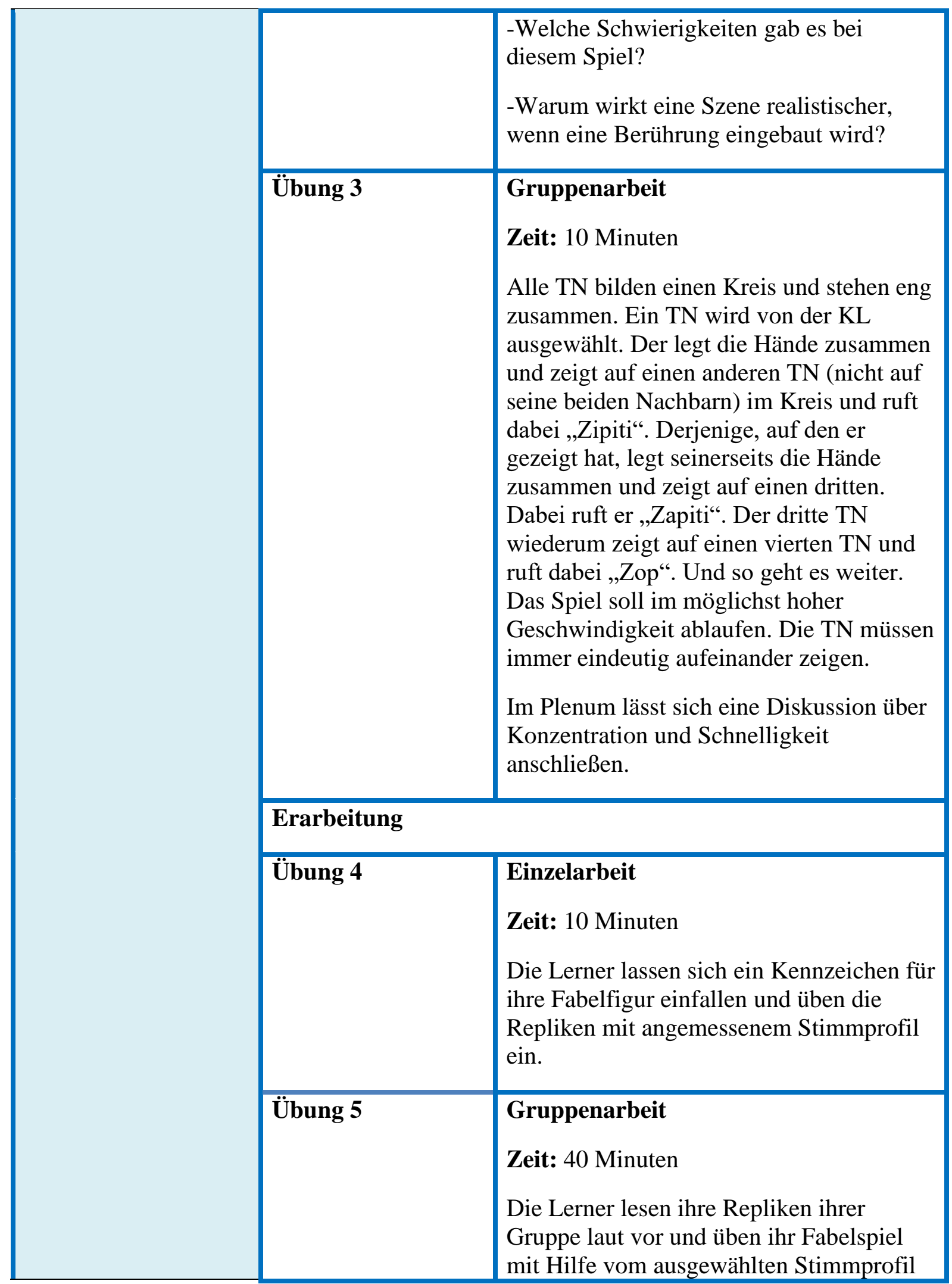




\section{Nordic Journal of Modern Language Methodology}

2019, 7 (1), 165-220 (Part B - Not peer reviewed)

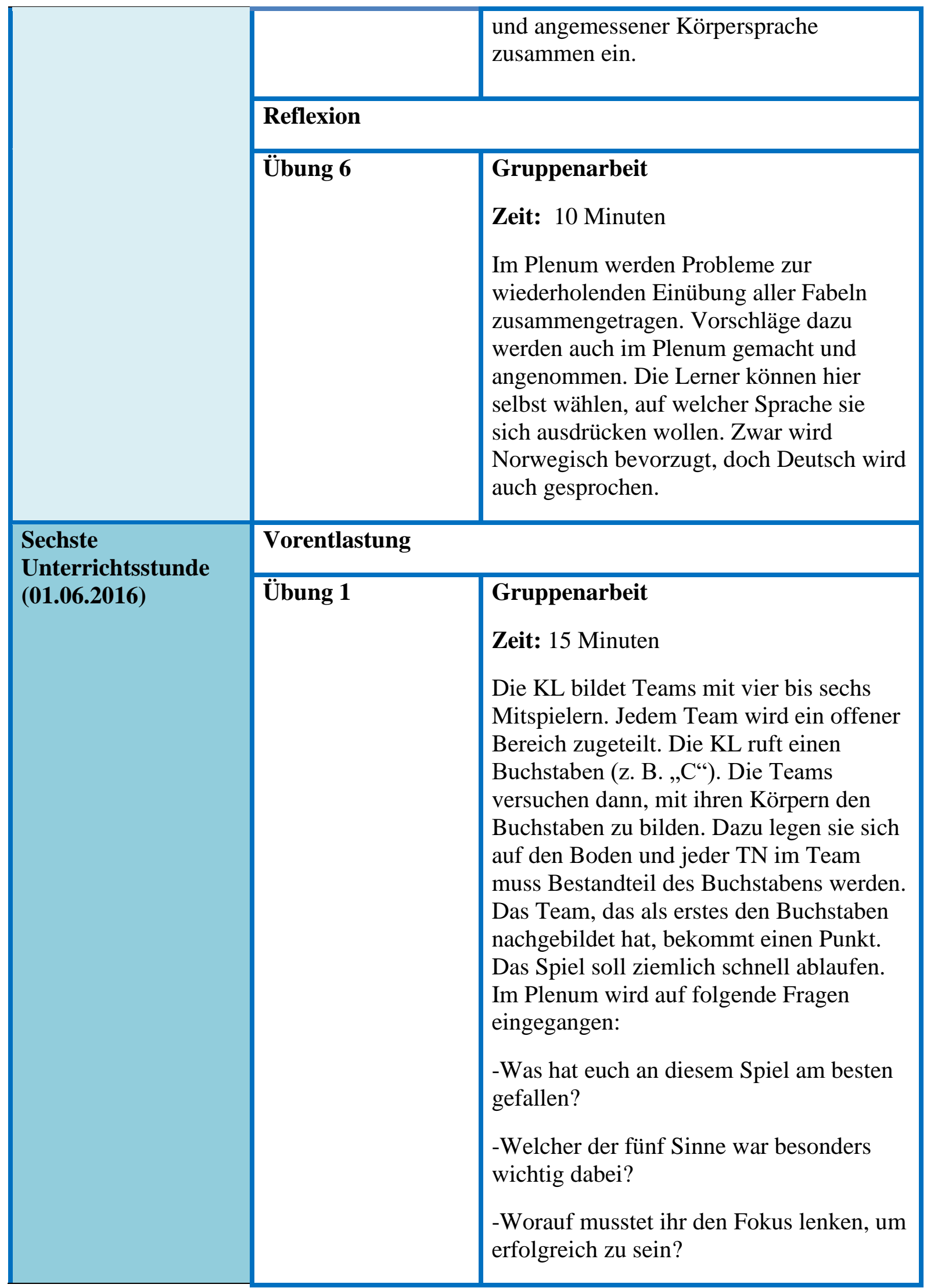




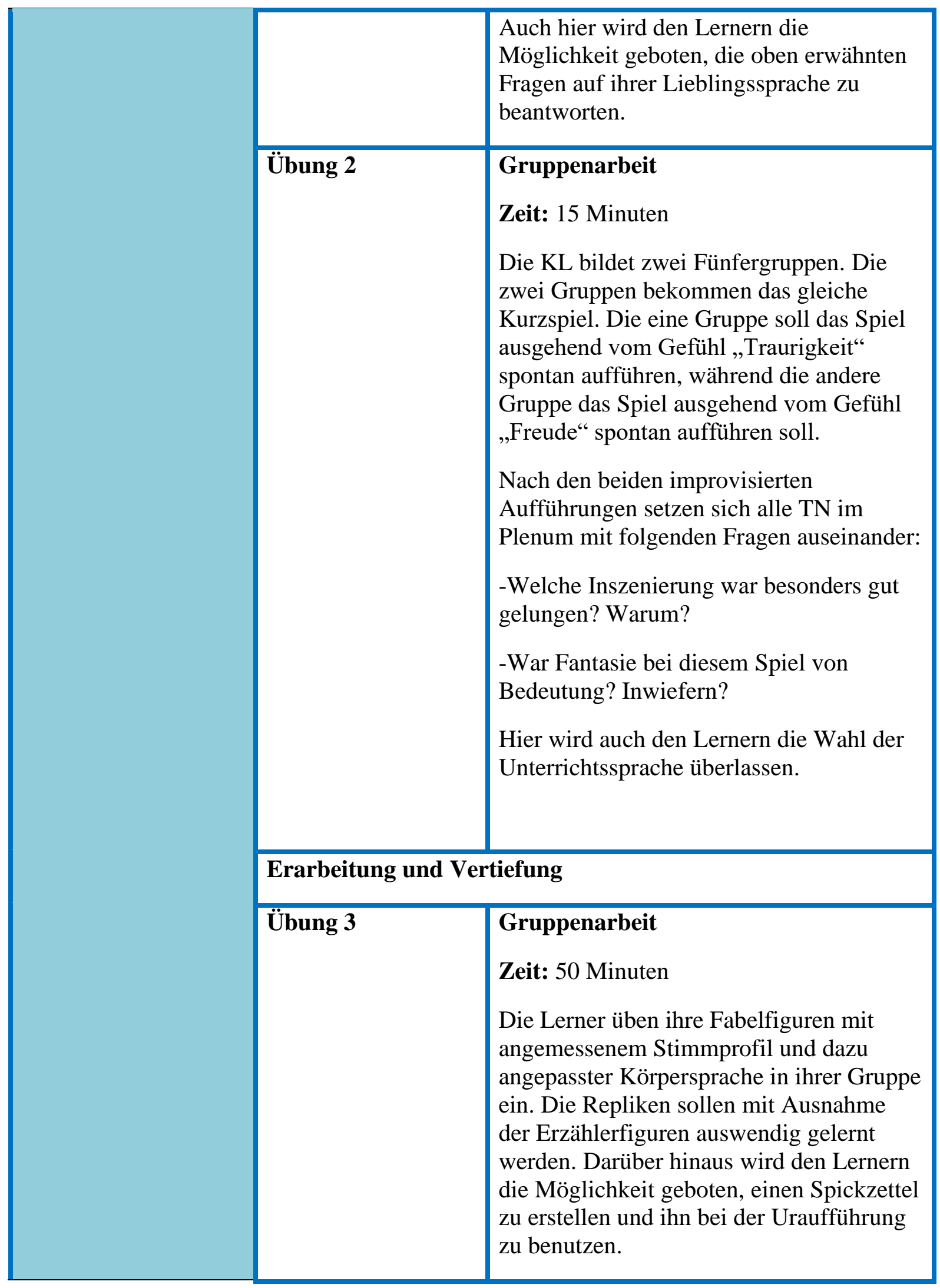




\section{Nordic Journal of Modern Language Methodology}

2019, 7 (1), 165-220 (Part B - Not peer reviewed)

\begin{tabular}{|c|c|c|}
\hline & Zielaufgabe & $\begin{array}{l}\text { Gruppenarbeit } \\
\text { Zeit: } 10 \text { Minuten } \\
\text { Erste Audioaufnahme der Fabeln: Die } \\
\text { Lerner sollen die Repliken ihrer } \\
\text { Fabelfiguren mit einem Handy aufnehmen. } \\
\text { Der Anfang muss wie folgt lauten: „Hallo. } \\
\text { Wir werden die Fabel X hier vorlesen. Der } \\
\text { Erzähler Nr. } 1 \text { ist Z, der Erzähler Nr. } 2 \text { ist } \\
\text { Y, der Tiger/Löwe/Affe... ist B, usw.“ }\end{array}$ \\
\hline \multirow{4}{*}{$\begin{array}{l}\text { Siebte } \\
\text { Unterrichtsstunde } \\
(07.06 .2016)\end{array}$} & \multicolumn{2}{|c|}{ Vorentlastung } \\
\hline & Übung 1 & $\begin{array}{l}\text { Gruppenarbeit } \\
\text { Zeit: } 10 \text { Minuten } \\
\text { Die TN stellen sich im Kreis auf. Sie } \\
\text { sollen gleich versuchen, so weit wie } \\
\text { möglich zu zählen. Das Schwierige dabei } \\
\text { ist, dass es nicht jeder für sich allein } \\
\text { versuchen soll, sondern alle zusammen in } \\
\text { der Gruppe. Man darf aber nur eine Zahl } \\
\text { sagen. Wenn eine Zahl von zwei oder } \\
\text { mehreren TN gleichzeitig gesagt wird, } \\
\text { muss die Gruppe wieder von vorne } \\
\text { anfangen. } \\
\text { Diese Fragen werden am Ende des Spiels } \\
\text { im Plenum angesprochen: } \\
\text {-Warum konntet ihr manchmal weiter } \\
\text { zählen? } \\
\text {-Ist bei diesem Spiel ein Spielleiter } \\
\text { sinnvoll? Was kann er machen? } \\
\text { Die Fragen können auf Deutsch oder auf } \\
\text { Norwegisch beantwortet werden. }\end{array}$ \\
\hline & \multicolumn{2}{|c|}{ Erarbeitung und Vertiefung } \\
\hline & Übung 2 & $\begin{array}{l}\text { Gruppenarbeit } \\
\text { Zeit: } 80 \text { Minuten } \\
\text { Die Lerner üben ihre Fabelfiguren mit } \\
\text { angemessenem Stimmprofil und dazu }\end{array}$ \\
\hline
\end{tabular}




\section{Nordic Journal of Modern Language Methodology}

2019, 7 (1), 165-220 (Part B - Not peer reviewed)

\begin{tabular}{|c|c|c|}
\hline & & $\begin{array}{l}\text { angepasster Körpersprache in ihrer Gruppe } \\
\text { ein. Wenn sie sich bereit erklären, eine } \\
\text { Generalprobe durchzuführen, rufen sie die } \\
\text { SL und ihre deutschsprachige Assistentin. } \\
\text { Als Publikum schauen sich die SL und die } \\
\text { Assistentin die Inszenierung jeder Fabel } \\
\text { an. Danach geben sie nützliche Tipps für } \\
\text { eine richtige Aussprache und } \\
\text { Körpersprache sowie für das ausgewählte } \\
\text { Stimmprofil, wenn es nötig ist. }\end{array}$ \\
\hline \multirow{5}{*}{$\begin{array}{l}\text { Achte } \\
\text { Unterrichtsstunde } \\
(\mathbf{0 8 . 0 6 . 2 0 1 6 )}\end{array}$} & \multicolumn{2}{|c|}{ Vorentlastung } \\
\hline & Übung 1 & $\begin{array}{l}\text { Gruppenarbeit } \\
\text { Zeit: } 10 \text { Minuten } \\
\text { Die Lerner hören Wörter mit den } \\
\text { Zischlauten } / \mathrm{J} / / \mathrm{s} / \text { und /z/ und sprechen sie } \\
\text { nach. Danach hören sie Wortpaare mit den } \\
\text { erwähnten Zischlauten, welche sie } \\
\text { nachsprechen. Wortpaare und Wörter } \\
\text { werden gemischt gehört und in zwei } \\
\text { Spalten (/s/+/z/ oder / } / \text { /) eingetragen. Die } \\
\text { Ergebnisse werden im Plenum } \\
\text { zusammengetragen. }\end{array}$ \\
\hline & Übung 2 & $\begin{array}{l}\text { Partnerarbeit und Gruppenarbeit } \\
\text { Zeit: } 10 \text { Minuten } \\
\text { Zu zweit versuchen die Lerner, ausgehend } \\
\text { von den gehörten Wörtern und Wortpaaren } \\
\text { die Regeln für die Aussprache von /z/, /s/ } \\
\text { und /S/- Lauten für die Buchstaben „s“ und } \\
\text { „sch“ herauszufinden. Die Ergebnisse } \\
\text { werden im Plenum zusammengetragen. }\end{array}$ \\
\hline & Übung 3 & $\begin{array}{l}\text { Gruppenarbeit } \\
\text { Zeit: } 10 \text { Minuten } \\
\text { Die Lerner hören Wörter und Wortpaare } \\
\text { mit den Zischlauten /J/, /s/ und /z/ und } \\
\text { sprechen sie mit verschiedenen Emotionen } \\
\text { nach. }\end{array}$ \\
\hline & Übung 4 & Gruppenarbeit \\
\hline
\end{tabular}




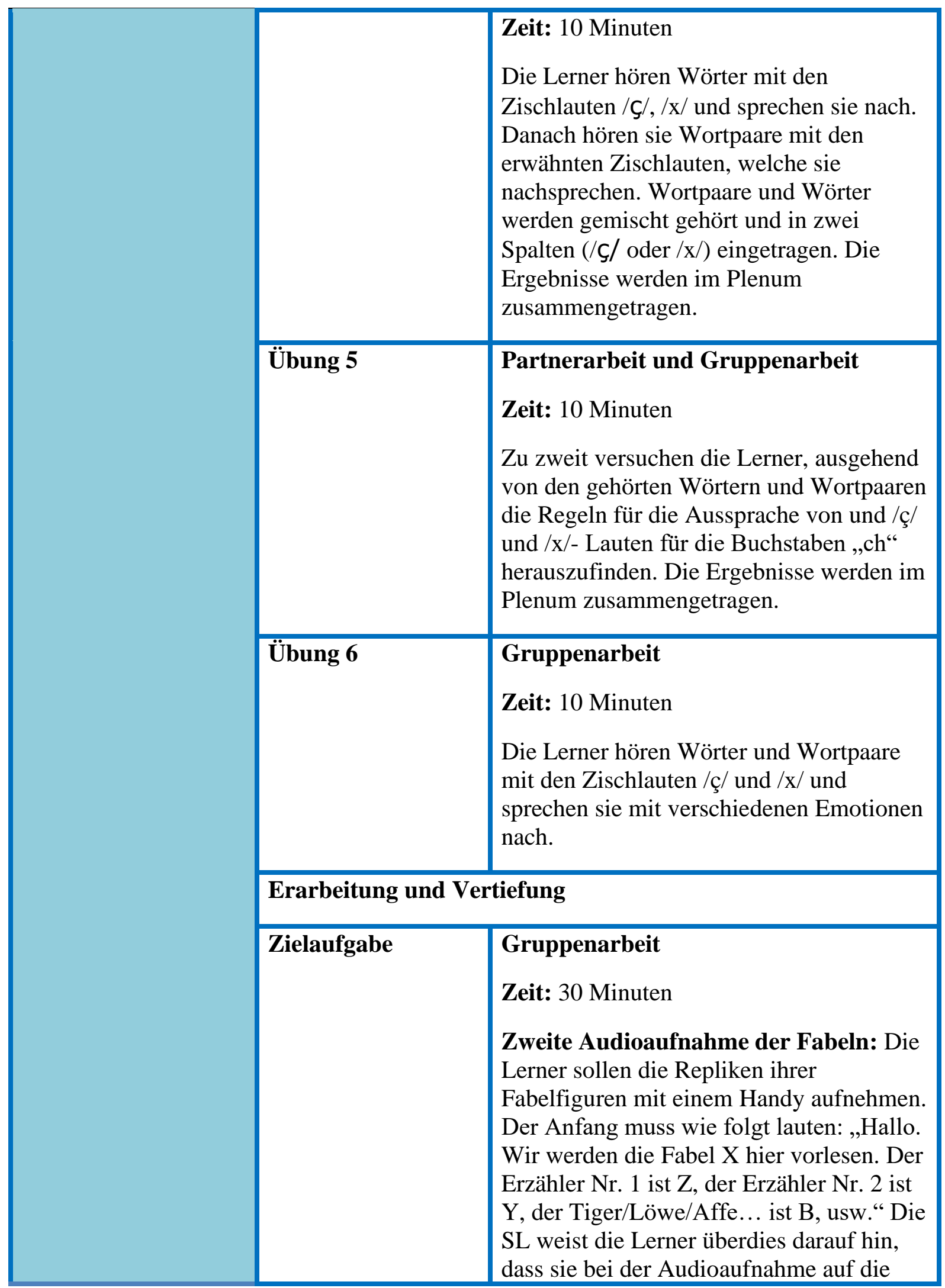




\section{Nordic Journal of Modern Language Methodology}

2019, 7 (1), 165-220 (Part B - Not peer reviewed)

\begin{tabular}{|c|c|c|}
\hline & & $\begin{array}{l}\text { Aussprache der bereits bekannten } \\
\text { Zischlaute achten sollen. } \\
\text { Nach der Audioaufnahme wird ein } \\
\text { individuelles Gespräch mit der SL über die } \\
\text { Gesamtnote im Fach Deutsch II geführt. } \\
\text { Währenddessen sollen die Lerner in } \\
\text { Gruppen für die Uraufführung ihrer Fabeln } \\
\text { proben. }\end{array}$ \\
\hline \multirow{6}{*}{$\begin{array}{l}\text { Neunte } \\
\text { Unterrichtsstunde } \\
(\mathbf{1 4 . 0 6 . 2 0 1 6 )}\end{array}$} & \multicolumn{2}{|c|}{ Vorentlastung } \\
\hline & Übung 1 & $\begin{array}{l}\text { Gruppenarbeit } \\
\text { Zeit: } 10 \text { Minuten } \\
\text { Bei dieser Atem- und } \\
\text { Konzentrationsübung erzählt die SL ihren } \\
\text { Lernern, was sie machen werden und } \\
\text { warum sie gleich vor dem Auftritt auf } \\
\text { richtiges Atmen achten sollten. Dann gibt } \\
\text { sie ihnen konkrete Anweisungen. Für diese } \\
\text { Übung sieht die KL zuerst zwei bis drei } \\
\text { Minuten voraus. Bei der späteren } \\
\text { Wiederholung weitet sie auf drei bis fünf } \\
\text { Minuten aus. Wichtig ist, dass die Lerner } \\
\text { bei der Übung erst einmal ein wenig } \\
\text { Ausdauer bekommen. }\end{array}$ \\
\hline & \multicolumn{2}{|c|}{ Erarbeitung und Vertiefung } \\
\hline & Zielaufgabe & $\begin{array}{l}\text { Gruppenarbeit } \\
\text { Zeit: } 50 \text { Minuten } \\
\text { Die Fabeln werden in einem } \\
\text { Klassenzimmer vor anderen } \\
\text { Deutschklassen, Lehrern und der } \\
\text { Schulleitung inszeniert. Die TN dürfen } \\
\text { dabei einen Souffleur oder/und selbst } \\
\text { erstellte Spickzettel zu Hilfe nehmen. }\end{array}$ \\
\hline & \multicolumn{2}{|l|}{ Reflexion } \\
\hline & Übung 2 & $\begin{array}{l}\text { Einzelarbeit und Gruppenarbeit } \\
\text { Zeit: } 30 \text { Minuten }\end{array}$ \\
\hline
\end{tabular}




\section{Nordic Journal of Modern Language Methodology}

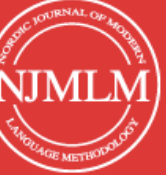

2019, 7 (1), 165-220 (Part B - Not peer reviewed)

\begin{tabular}{|l|l|}
\hline Jeder TN füllt einen Fragebogen zum \\
durchgeführten Theaterprojekt aus. Die \\
acht auf Deutsch gestellten Fragen sollen \\
in vollständigen Sätzen auf Norwegisch \\
und im Einzelnen beantwortet werden. \\
Danach werden interessante Ereignisse im \\
Plenum zusammengetragen. Dafür sitzen \\
alle TN im Kreis auf Stühlen.
\end{tabular}

Dritter Unterrichtsblock: Phase der Reflexion

Unterrichtsstunden: 1 US à 90 Minuten (eine fünfminutige Pause inklusive)

\section{Lernziele:}

- $\quad$ sich des Unterschieds zwischen wichtigen Zischlauten bewusst zu sein

- wichtige Zischlaute aus einem unbekannten Text richtig auszusprechen

- über den gesamten Eindruck vom durchgeführten Theaterprojekt zu reflektieren und sich auf kreative Weise dazu zu äußern

Thema: Lesezeit (Lektion 15 aus Weitblick 2)

\begin{tabular}{|c|c|c|}
\hline \multirow{2}{*}{$\begin{array}{l}\text { Zehnte } \\
\text { Unterrichtsstunde } \\
(\mathbf{1 5 . 0 6 . 2 0 1 6 )}\end{array}$} & \multicolumn{2}{|c|}{ Vorentlastung } \\
\hline & Übung 1 & $\begin{array}{l}\text { Gruppenarbeit } \\
\text { Zeit: } 20 \text { Minuten } \\
\text { Jeder TN bekommt ein Labyrinth. Die KL hat das } \\
\text { passende Labyrinth vor sich und entscheidet, } \\
\text { welche drei Wörter sie von ihrem Labyrinth } \\
\text { nacheinander vorliest, d. h. sie muss sich jedes } \\
\text { Mal für eins (z. B. „Mädchen“, „Streichhölzer“ } \\
\text { und „Päckchen“) von zwei möglichen Wörtern } \\
\text { entscheiden. Die TN wählen aus, welchen der } \\
\text { alternativen Laute (/ç/, /x/, /s/, /z/, /J/) das Wort } \\
\text { enthält (z. B. Von „Mädchen“ aus geht der Weg } \\
\text { nach „Streichhölzer“" weiter). Dann bittet die SL } \\
\text { einen TN, das Bild am Ende des Wegs zu } \\
\text { beschreiben (z. B. „Auf dem Bild sehe ich ein } \\
\text { Mädchen, ein Päckchen und Streichhölzer“). Die } \\
\text { anderen TN achten gut darauf, dass die Zischlaute } \\
\text { richtig ausgesprochen werden. Ziel ist es, Spaß }\end{array}$ \\
\hline
\end{tabular}




\begin{tabular}{|c|c|}
\hline & $\begin{array}{l}\text { am Spiel zu haben und die schon bekannten } \\
\text { Zischlaute aufzufrischen }{ }^{19} \text {. }\end{array}$ \\
\hline \multicolumn{2}{|c|}{ Erarbeitung und Vertiefung } \\
\hline Aufgabe 1 & $\begin{array}{l}\text { Gruppenarbeit } \\
\text { Zeit: } 40 \text { Minuten } \\
\text { Dritte Audioaufnahme eines unbekannten } \\
\text { Textes: Die Lerner bekommen einen unbekannten } \\
\text { Text mit vielen herausfordernden Zischlauten }{ }^{20} \text {. } \\
\text { Sie teilen den Text in Abschnitte ein. Jedes } \\
\text { Gruppenmitglied wird verantwortlich für einen } \\
\text { Textabschnitt. Die TN lesen mehrmals ihren } \\
\text { ausgewählten Textabschnitt für sich vor. Dann } \\
\text { nehmen sie sich mit einem Handy auf. Der } \\
\text { Anfang muss wie folgt lauten: „Hallo. Wir } \\
\text { werden den Text „Ein Dachs und ein Luchs“ hier } \\
\text { vorlesen. Wir sind X, Z, Y, usw.“ }\end{array}$ \\
\hline \multicolumn{2}{|l|}{ Reflexion } \\
\hline Aufgabe 2 & $\begin{array}{l}\text { Gruppenarbeit } \\
\text { Zeit: } 15 \text { Minuten } \\
\text { Die TN sitzen im Kreis auf Stühlen. Die KL hängt } \\
\text { einen Poster mit zwei Smileys an die Wand: das } \\
\text { eine hat ein lächelndes Gesicht und das andere, } \\
\text { ein trauriges Gesicht. Jeder TN bekommt einen } \\
\text { Stift und geht zum Poster, wo er eine } \\
\text { stichwortartige Rückmeldung in die gewünschte } \\
\text { Smiley-Spalte eintragen soll. Nachdem alle TN } \\
\text { ihre schriftlichen Feedbacks gegeben haben, liest }\end{array}$ \\
\hline
\end{tabular}

\footnotetext{
${ }^{19}$ Siehe Reinke \& Hirschfeld, 2016, S. 33f.

${ }^{20}$ Der unbekannte Text ist ein Textausschnitt aus einem Märchen und lautet wie folgt: „Ein Dachs und ein Luchs liefen durch den Wald. Sie wollten am Fluss Lachse fangen. Es war ein schöner Tag zu erwarten, und der Dachs hatte sogar ein Fläschchen Rotwein mitgebracht. Da trafen sie an einer Wegkreuzung den Herrn Fuchs, der mit seiner Freundin, einer jungen Füchsin, auch unterwegs war. Die beiden sahen sich so ähnlich, dass man sie hätte verwechseln können, der Fuchs hatte lediglich einen etwas buschigeren Schwanz und die Nase der Füchsin war ein bisschen länger als die des Fuchses. „Guten Tag, Herr Dachs, guten Tag, Herr Fuchs“, sagte der Fuchs mit bisschen zu viel Höflichkeit. „Wohin des Wegs?“ - „Wir wollen am Fluss Lachse fangen“, sagte der Luchs. Und der Dachs sagte „Kommen Sie doch ein bisschen mit, Herr Fuchs, dann macht’s mehr Spaß“! Da flüsterte der Fuchs seiner Füchsin etwas ins Ohr. Er gab ihr noch ein kleines Küsschen, und im nächsten Moment schon war sie verschwunden. „Jetzt wird es aber höchste Zeit, dass wir zum Fluss kommen“, sagte der Luchs, und der Fuchs ging mit dem Dachs und dem Luchs zum Fluss. Als sie am Fluss ankamen, ..."(Rug, 2012, S. 55).
} 


\section{Nordic Journal of Modern Language Methodology}

2019, 7 (1), 165-220 (Part B - Not peer reviewed)

\begin{tabular}{|l|l|}
\hline Aufgabe 3 & $\begin{array}{l}\text { die SL alle eingetragenen Ereignisse vor. Die } \\
\text { Aufgabe endet mit einem Beifallsturm. }\end{array}$ \\
\hline & $\begin{array}{l}\text { Gruppenarbeit } \\
\text { Zeit: } 15 \text { Minuten } \\
\text { Die SL hängt eine Landkarte von Deutschland an } \\
\text { eine Pinnwand. Auf der Landkarte kreist sie die } \\
\text { Landeshauptstadt Berlin mit einem roten Stift ein. } \\
\text { Dann stellt sie ihren TN die Frage, wie gut ihnen } \\
\text { das Theaterprojekt gefallen hat. Berlin bedeutet } \\
\text {,Sehr gut“. Dann bittet sie jeden TN, sich zur } \\
\text { Landkarte zu begeben und eine Reißzwecke in die } \\
\text { Pinnwand zu drücken. Jeder TN muss aber auf } \\
\text { Berlin achten: Je nachdem wie enttäuscht er sich } \\
\text { über das Theaterprojekt oder wie zufrieden er sich } \\
\text { mit dem Theaterprojekt fühlt, drückt er seine } \\
\text { Reißzwecke am weitesten von Berlin entfernt } \\
\text { oder am nächsten zu Berlin. } \\
\text { Am Ende werfen alle TN einen Blick auf die } \\
\text { Landkarte mit allen Reißzwecken und klatschen } \\
\text { zum Schluss Beifall. }\end{array}$ \\
\hline
\end{tabular}

3. Fünf dramatische Tierfabeln von Olaf Heuser: Die schlaue Füchsin und der Tiger aus China, Der Hase und die Mango aus Indien, Der Löwe und die Maus, Der Fuchs und der Rabe von Aesop und Zwei Freunde und ein Bär von Aesop

\section{Die schlaue Füchsin und der Tiger}

(4-6 Rollen)

ErzählerIn 1 $* * *$

ErzählerIn 2 $* * *$

Füchsin $* * *$

Tiger $* * *$

Frau *

Kind * 


\section{Nordic Journal of Modern Language Methodology}

ErzählerIn 1 Die schlaue Füchsin und der Tiger.

ErzählerIn 2

Eine Fabel aus China.

Keiner im Dschungel kann ihm entkommen: dem Tiger. Ameisen, Mäuse, Tapire, ja sogar die Elefanten müssen sich in Acht nehmen vor dem großen Raubtier.

ErzählerIn 1 Aber eines Tages: die Katastrophe. Eine kleine Füchsin sah sich plötzlich Aug in Aug mit dem fürchterlichen Untier.

Tiger

Füchsin

Hallo, Mittagessen. Schön dich zu sehen.

ErzählerIn 2

Oje, jetzt ist es aus mit mir.

Füchsin

Kein Ausweg in Sicht: kein Busch, kein Loch um sich zu verstecken.

Ich muss mir was einfallen lassen. Was mache ich? Angriff ist die beste

Verteidigung.

ErzählerIn 1 Der Tiger risss ein Maul schon weit auf.

Füchsin

$\mathrm{He}$, du altes Großmaul. Mach die Klappe wieder zu. Ich werde dir gleich eine

Tiger

Lektion erteilen, die du nicht vergessen wirst.

Häh? Seit wann wehrt sich mein Mittagessen?

Du willst mir eine Lektion erteilen?

Dass ich nicht lache.

\section{ErzählerIn 2}

Und der Tiger lachte, dass es den ganzen Dschungel schüttelte.

Füchsin

Tiger

Füchsin

Tiger

Füchsin

Tiger

ErzählerIn 1
Du brauchst dich gar nicht so aufzuspielen.

Ich bin ja noch viel fürchterlicher als du!

$\mathrm{Du}$, fürchterlicher als ich? Lachhaft. Vor mir fürchten sich sogar die Menschen mit ihren spitzen Lanzen. Ich bin der König des Dschungels.

Ja, vielleicht fürchten sie sich vor dir, aber vor mir laufen sie in Scharen davon, wenn sie mich sehen.

Du faselst ja irgendwas daher.

Willst du einen Beweis? Dann folge mir, du Schwächling.

Ich träume wohl?

Dachte der Tiger, völlig verwirrt. So ein kleines Tier sollte den Menschen mehr Angst einjagen als er? 


\section{Nordic Journal of Modern Language Methodology}

\section{ErzählerIn 2}

Die Füchsin lief nun voran, in Richtung des Dorfes der Menschen.

ErzählerIn 1

Dabei achtete sie darauf, immer im hohen Gras zu bleiben.

ErzählerIn 2 Der Tiger sprang in großen Sprüngen hinter ihr her.

Füchsin Na, wo bleibst du, du gestreifter Fellsack?

Tiger Du entkommst mir schon nicht, Füchslein.

ErzählerIn 1 Als die beiden auf das Dorf zuliefen, rannten die Menschen in panischer Flucht in ihre Häuser.

Frau

Hilfe, Kinder. Schnell ins Haus. Lauft, lauft!

Kind

Mama, ich hab` Angst. Der, der, der Ti...

Frau

Oh, wir sind verloren. Wir werden alle gefressen.

ErzählerIn 2 Die Füchsin hielt an im hohen Gras.

ErzählerIn 1 Mit dem Tiger hinter sich.

Füchsin

Tiger

$\mathrm{Na}$, siehst du, wie sie geflohen sind, als ich auf sie zugelaufen bin? In Todesangst!

Füchsin Naja.

Was heißt hier 'Naja': sie haben mindestens so viel Angst vor mir wie vor dir. Das musst du schon zugeben.

Tiger

Füchsin

ErzählerIn 1

Füchsin

ErzählerIn 2

Füchsin ErzählerIn 1 Vom aber Tiger hatte sie seit dem nichts mehr zu befürchten.
Alle Achtung, das hätte ich nicht gedacht. Du bist mir ebenbürtig. Wenn ich der König des Dschungels bin, bist du...

...die Königin?!

Und der Tiger war, wie alle Angeber, ebenso ängstlich wie dumm, und lief schleunigst weg von diesem schrecklichen Tier mit dem buschigen Schwanz.

Puh, nochmal Glück gehabt. Den bin ich los.

Und stolz sie lief nach Hause.

Ein schlauer Kopf kann fürchterlicher sein als spitze Zähne und lautes Gebrüll. 


\section{Nordic Journal of Modern Language Methodology}

2019, 7 (1), 165-220 (Part B - Not peer reviewed)

\section{Der Hase und die Mango}

(8-9 Rollen)

ErzählerIn 1 $* * *$

ErzählerIn 2 $* * *$

Ziege $* *$

Nilpferd $* *$

Löwe $* *$

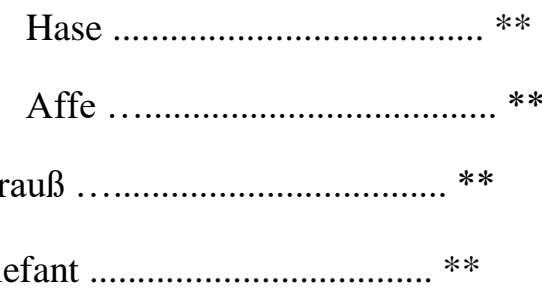

*** viel zu lesen ** mittelviel $\mathrm{zu}$ lesen * wenig zu lesen

ErzählerIn 1 Der Hase und die Mango. Eine Fabel aus Indien.

ErzählerIn 2 Unsere Geschichte handelt von einem Hasen.

ErzählerIn 1 Von einem sehr ängstlichen Hasen.

ErzählerIn 2 Eines Tages lag unser Hase unter einem Mangobaum.

ErzählerIn 1 Und dachte nach.

Hase Wie das wohl ist, wenn die Welt untergeht? Vielleicht gibt es einen Knall, die Erde geht auf und verschluckt mich?

ErzählerIn 2 Über dem vielen Nachdenken schlief unser Hase ein.

ErzählerIn 1 Ganz friedlich schlief er da in der Mittagssonne.

ErzählerIn 2 Als plötzlich...

ErzählerIn 1 Bummmm!

Hase Ha, was war das? Was war das?

ErzählerIn 2 Er sprang auf.

ErzählerIn 1 Er lief hin, er lief her.

Hase

Die Welt geht unter, die Welt geht unter, die Welt...

ErzählerIn 2 Und der Hase rannte los, so schnell er konnte.

ErzählerIn 2 Und traf am Weg einen Affen. 


\section{Nordic Journal of Modern Language Methodology}

2019, 7 (1), 165-220 (Part B - Not peer reviewed)

Affe

Hase

Affe

Hase

Affe

Hase

ErzählerIn 1

ErzählerIn 2

Ziege

Affe

Ziege

Affe

ErzählerIn 2 Jetzt waren sie schon zu dritt.

ErzählerIn 1 Da begegneten sie einem Vogel Strauß.

Strauß Na, ihr könnt ja rennen!

Ziege

Strauß

Ziege

ErzählerIn 2 Und der Strauß lief mit.

ErzählerIn 1 Da stand am Fluß ein Nilpferd.

Nilpferd

Strauß

Nilpferd

He, was rennst du denn so?

Das solltest du besser auch tun.

Wieso?

Die Welt geht unter!

Was?

Renn'!

Die Welt geht unter.

Was? Wieso? Warum?

Die Welt geht unter.

Sagt wer?

Lauf' oder willst du sterben?

Die Welt geht unter!

Was du nicht sagst.
Ich hab's gehört, sie öffnet sich und wird uns alle verschlucken.

Da auch der Affe nicht der mutigste war, rannte er mit.

Da stand am Weg eine Ziege, die wiederkäute.

He, ihr beiden. Was hetzt ihr denn so? Ihr habt es wohl eilig?

Der Affe. Der weiß es vom Hasen. Der hat's gehört und gesehen.

Leute, nicht so hastig, es ist schließlich Mittagszeit. 


\section{Nordic Journal of Modern Language Methodology}

Strauß

ErzählerIn 2 Schwerfällig setzte sich das Nilpferd in Bewegung.

ErzählerIn 1 Sie liefen an einem Elefanten vorbei.

Elefant

Nilpferd

Elefant

Nilpferd

ErzählerIn 1 Jetzt waren sie schon zu sechst:

ErzählerIn 2 Der Hase, der Affe, die Ziege.

ErzählerIn 1 Der Strauß, das Nilpferd und der Elefant.

ErzählerIn 2 In ihrer Angst und Kopflosigkeit merkte sie nicht, dass sie auf einen tiefen Abgrund zu rannten,...

ErzählerIn 1 ...bei dem der Löwen seine Mittagsruhe hielt.

ErzählerIn 2 Als er das Getrampel der näherkommenden Horde hörte, rief er:

Löwe Was? Was tut ihr? Da geht's nicht weiter!

Elefant Renn'! Der Hase...

Löwe Stoooopp!!!

ErzählerIn 2 Und der Löwe brüllte so laut und fürchterlich, dass alle stehen blieben.

ErzählerIn 1 Und wild übereinander fielen.

Löwe

Was ist denn in euch gefahren? Seid ihr verrückt geworden?

Elefant

Die Welt geht doch unter.

Löwe

Elefant

Sagt wer?

Das Nilpferd.

Nilpferd Der Strauß.

Strauß Die Ziege. 
Ziege

Affe

Hase

Löwe

Hase

Löwe

ErzählerIn 2

ErzählerIn 1

Hase

Löwe

Hase

ErzählerIn 2

Löwe

Hase

Löwe

ErzählerIn 1

Löwe
Der Affe.

Der Hase.

Ich war dabei!

So, so, du warst dabei. Dann zeig mir doch mal, wo du dabei warst.

Es war beim Mangobaum.

Dann auf zum Mangobaum.

Und sie machten sich gemeinsam auf zum Mangobaum.

Dort angekommen, schaute sich der Löwe alles sehr genau an.

Hier habe ich gelegen und friedlich geschlafen.

Und dann?

Dann hat es furchtbar gerumpelt. Ich bin aufgesprungen und losgerannt.

In dem Moment fiel eine reife Mango vom Baum, den Tieren genau vor die Nase.

Hat sich das ungefähr so angehört, dein Weltuntergang?

Äh, ja, so ungefähr...

Tja, das ist dann wohl des Rätsels Lösung. Ein reife Mango! Ich gebe euch einen guten Rat: prüft erst mal das, was euch einer sagt. Und entscheidet dann, ob ihr mit in den Untergang rennen wollt.

Da schwiegen die Tiere betreten und beschämt.

Naja, ist ja nochmal gut gegangen. Dann lasst uns doch jetzt die guten Mangos essen.

\section{Der Löwe und die Maus}

(3-4 Rollen)

ErzählerIn 1 $* * *$

ErzählerIn 2 $* * *$

Maus *** *** 


\section{Nordic Journal of Modern Language Methodology}

2019, 7 (1), 165-220 (Part B - Not peer reviewed)

ErzählerIn 1

ErzählerIn 2

ErzählerIn 1

Maus

ErzählerIn 2

Löwe

Maus

ErzählerIn 1

Löwe

Maus

ErzählerIn 2

ErzählerIn 1

Löwe

ErzählerIn 2

Maus

ErzählerIn 1

Löwe

ErzählerIn 2

Löwe

ErzählerIn 1
Der Löwe und die Maus. Ein[e] Fabel von Äsop.

Einmal lief eine Maus in der Wüste herum und suchte Futter.

Da stolperte sie über den Schwanz eines schlafenden

Löwen.

Hoppla. Tut mir sehr leid.

Der Löwe wachte auf und packte die kleine Maus.

Wer wagt es, den König der Tiere zu wecken? Eine Maus?! Na, dich fresse ich doch als kleinen Leckerbissen zwischendurch.

$\mathrm{Oh}$, bitte friss mich nicht. Ich muss doch für meine Kinder Futter finden.

Ich verspreche dir auch, wenn du einmal in Not bist, werde ich dir helfen.

Der Löwe lachte sehr darüber.

Hahaha. Wie soll ein so kleines Mäuschen mir helfen können? Lächerlich! Aber weil ich so lachen konnte, lasse ich dich laufen.

Vielen Dank. Du sollst es nicht bedauern.

Nach nicht langer Zeit wurde der Löwe von Jägern in einem Netz gefangen.

Er brüllte und riss an dem Netz, konnte sich aber nicht befreien.

Aaaah. Gleich zerreiße ich das Netz, dann könnt ihr was erleben.

Von weitem hörte die Maus das Brüllen.

Schnell lief sie zu dem Löwen.

Wie kann ich dem Löwen nur helfen?

Ah, ich habe eine Idee.

Ich zernage die Stricke des Netzes.

Das tat sie und der Löwe war wieder frei.

Vielen Dank, kleine Maus.

Ich werde dich nie mehr auslachen.

Jetzt wußte er:

Auch der Kleinste kann dem Größten in der Not helfen.

Von da an waren die kleine Maus und der große Löwe die besten Freunde. 


\section{Nordic Journal of Modern Language Methodology}

\section{Der Fuchs und der Rabe}

(3-4 Rollen)

Erzähler 1 $* * *$

Erzähler 2 $* * *$

Rabe ** Fuchs $* *$

\section{*** große Rollen ** mittlere Rollen * kleine Rolle}

Erzähler 1

Erzähler 2

Erzähler 1

Erzähler 2

Fuchs

Erzähler 1

Erzähler 2

Rabe

Erzähler 1

Erzähler 2

Erzähler 1

Rabe

Fuchs

Rabe

Fuchs

Rabe

Erzähler 2

Fuchs

Rabe

Fuchs

Erzähler [2]
Der Fuchs und der Raabe.

Ein Raabe sitzt ${ }^{21}$ auf einem Baum.

Er hat einen Käse im Schnabel.

Da kommt ein Fuchs. Er riecht den Käse.

Guten Tag, Raabe. Du bist sehr schön. Kannst du auch schön singen? Bitte singe doch für mich!

Das schmeichelt dem Raben.

Der Rabe reißt den Schnabel auf. Er krächzt los.

Kraa. Kraa. Kraa. Kraaaa. Kraaaaa.

Was passiert?

Der Käse fällt aus dem Schnabel auf den Boden.

Der Fuchs schnappt sich den Käse.

Wie ist meine Stimme, Fuchs? Ist meine Stimme schön?

Danke für den feinen Käse, lieber Rabe.

Was?

Und deine Stimme ist schrecklich.

Das war ein böser Trick.

Der Fuchs lacht.

Hahaha.

Gib` mir den Käse zurück.

Tut mir leid. Der Käse ist sehr lecker. Danke und auf Wiedersehen.

Und der Fuchs läuft in den Wald.

\footnotetext{
${ }^{21}$ Fett und kursiv gedruckt wie im Original.
} 


\section{Nordic Journal of Modern Language Methodology}

\section{Erzähler 1}

Rabe
Der Rabe aber jammert.

Ohh, ich bin so dumm.

Kraa. Kraaaa. Kraaaaa. Kraaaaaaaaaa.

\section{Zwei Freunde und ein Bär}

(4-5 Rollen)

ErzählerIn 1 $* *$

ErzählerIn 2 $* *$

Freund 1 Freund 2

Bär

(Der Bär spricht nicht, sondern macht nur unheimliche Geräusche.)

$* * *$ viel zu lesen $* *$ mittelviel zu lesen * wenig zu lesen

ErzählerIn 1

ErzählerIn 2

ErzählerIn 1

Freund 1

Freund 2

Freund 1

Bär

Freund 2

ErzählerIn 2

Freund 2

Bär

Freund 1
Zwei Freunde und ein Bär. Eine Fabel von Äsop.

Zwei Freunde gingen gemeinsam in die Welt hinaus.

Sie versprachen sich, immer alles zu teilen und sich immer zu helfen.

Es wird langsam Nacht. Ich finde es ziemlich unheimlich hier.

Ja, der Wald ist sehr finster.

Wir sollten uns einen Platz für die Nacht suchen.

Oh, schau! Das kommt ein Bär!

(brummt laut)

Ein Bär? Hilfe! Was machen wir jetzt?

Zusammen hätten sie den Bären vielleicht verscheuchen können.

Ich klettere schnell auf diesen Baum.

(brüllt)

He, lass mich nicht allein. 


\section{Nordic Journal of Modern Language Methodology}

ErzählerIn 1

ErzählerIn 2

Bär

Freund 1

ErzählerIn 2

Bär

ErzählerIn 1

Bär

ErzählerIn 2

Bär

ErzählerIn 1

Bär

ErzählerIn 2

Freund 2

Freund 1

Freund 2

Freund 1

Freund 2

Freund 1

Freund 2

Freund 1
Der eine Freund konnte sich vor Angst kaum bewegen.

Auf dem Baum war auch nur Platz für einen Menschen.

(knurrt gefährlich)

Was soll ich nur machen?

Ich weiß: Ich werfe mich platt auf den Boden und stelle mich tot.

Er hatte einmal gehört, dass ein Bär nichts Totes frisst.

(brummt laut)

Der Bär kam nun herbei und schnüffelte.

(brummt sehr tief und schnüffelt)

Dann prustete der Bär in seine Ohren.

(prustet)

Der Bär warf den Wanderer mit der Schnauze ein paar Male hin und her.

(knurrt leise)

Dann trabte er tatsächlich davon, weil er ihn wohl wirklich für tot hielt.

Jetzt kann ich vom Baum runter. Der Bär ist weg.

Puh, noch mal Glück gehabt.

Das kann man wohl sagen.

Du hast gut reden: du warst ja auf dem sicheren Baum.

Der Bär war ziemlich dicht an dir dran.

Verdammt dicht.

Es hat ausgesehen, als ob der Bär dir etwas zugeflüstert habe.

Du wirst es nicht glauben: das hat er auch. Er hat mir ein Geheimnis verraten. Nur schade, dass ich es nicht früher gewusst habe. 
Freund 2

Freund 1

ErzählerIn 1
Wirklich? Welches Geheimnis?

Der Bär hat mir verraten: Lass dich nicht mit Menschen ein, die sagen, dass sie deine Freunde sind, die aber sofort verschwinden, sobald es gefährlich wird.

Von da ab ging jeder seiner eigenen Wege. 